\title{
A Habitable Fluvio-Lacustrine Environment at Yellowknife Bay, Gale Crater, Mars
}

J. P. Grotzinger ${ }^{*}$, D. Y. Sumner ${ }^{2}$, L.C. Kah ${ }^{3}$, K. Stack ${ }^{1}$, S. Gupta ${ }^{4}$, L. Edgar ${ }^{5}$, D. Rubin ${ }^{6, \dagger}$, K. Lewis $^{7}$, J. Schieber ${ }^{8}$, N. Mangold ${ }^{9}$, R. Milliken ${ }^{10}$, P. G. Conrad ${ }^{11}$, D. DesMarais ${ }^{12}$, J. Farmer ${ }^{5}$, K. Siebach $^{1}$, F. Calef III ${ }^{13}$, J. Hurowitz ${ }^{14}$, S. M. McLennan ${ }^{14}$, D. Ming ${ }^{15}$, D. Vaniman ${ }^{16}$, J. Crisp ${ }^{13}$, A. Vasavada ${ }^{13}$, K. S. Edgett ${ }^{17}$, M. Malin ${ }^{17}$, D. Blake ${ }^{12}$, R. Gellert ${ }^{18}$, P. Mahaffy ${ }^{11}$, R. C. Wiens ${ }^{19}$, S. Maurice ${ }^{20}$, J. A. Grant ${ }^{21}$, S. Wilson ${ }^{21}$, R. C. Anderson ${ }^{13}$, L. Beegle ${ }^{13}$, R. Arvidson ${ }^{22}$, B. Hallet $^{23}$, R. S. Sletten ${ }^{23}$, M. Rice ${ }^{1}$, J. Bell, III ${ }^{5}$, J. Griffes ${ }^{1}$, B. Ehlmann ${ }^{1,13}$, R. B. Anderson ${ }^{24}$, T. F. Bristow ${ }^{12}$, W. E. Dietrich ${ }^{25}$, G. Dromart ${ }^{26}$, J. Eigenbrode ${ }^{11}$, A. Fraeman ${ }^{22}$, C. Hardgrove ${ }^{17}$, K. Herkenhoff $^{24}$, L. Jandura ${ }^{13}$, G. Kocurek ${ }^{27}$, S. Lee ${ }^{13}$, L. A. Leshin ${ }^{28}$, R. Leveille ${ }^{29}$, D. Limonadi ${ }^{13}$, J. Maki ${ }^{13}$, S. McCloskey ${ }^{13}$, M. Meyer ${ }^{30}$, M. Minitti ${ }^{5}$, H. Newsom ${ }^{31}$, D. Oehler ${ }^{15}$, A. Okon ${ }^{13}$, M. Palucis $^{25}$, T. Parker ${ }^{13}$, S. Rowland ${ }^{32}$, M. Schmidt ${ }^{33}$, S. Squyres ${ }^{34}$, A. Steele ${ }^{35}$, E. Stolper ${ }^{1}$, R.

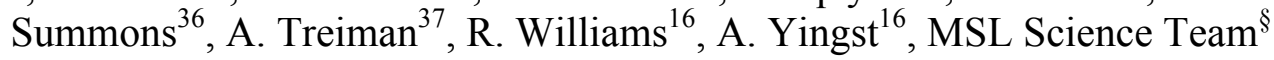

\section{Affiliations:}

${ }^{1}$ Division of Geologic and Planetary Sciences, California Institute of Technology, Pasadena, CA, 91125, USA.

${ }^{2}$ Department of Earth and Planetary Sciences, University of California, Davis, CA 95616, USA.

${ }^{3}$ Department of Earth and Planetary Sciences, University of Tennessee, Knoxville, TN 37996 , USA.

${ }^{4}$ Department of Earth Science and Engineering, Imperial College London, London, SW7 2AZ, UK.

${ }^{5}$ School of Earth and Space Exploration, Arizona State University, Tempe, AZ 85287, USA

${ }^{6}$ U.S. Geological Survey, Santa Cruz, CA 95060, USA.

${ }^{7}$ Department of Geoscience, Princeton University, Princeton, NJ 08544, USA

${ }^{8}$ Department of Geological Sciences, Indiana University, Bloomington, IN 47405, USA

${ }^{9}$ Laboratoire Planétologie et Géodynamique de Nantes, LPGN/CNRS UMR6112 and Université de Nantes, 44322 Nantes, France.

${ }^{10}$ Department of Geological Sciences, Brown University, Providence, RI 02912, USA.

${ }^{11}$ NASA Goddard Space Flight Center, Greenbelt, MD 20771, USA.

${ }^{12}$ Department of Space Sciences, NASA Ames Research Center, Moffett Field, CA 94035, USA.

${ }^{13}$ Jet Propulsion Laboratory, California Institute of Technology, Pasadena, CA 91109, USA. 
${ }^{14}$ Department of Geosciences, State University of New York State at Stony Brook, NY 117942100, USA.

${ }^{15}$ Jacobs Technology Inc, NASA Johnson Space Center, Houston, TX 77058, USA

${ }^{16}$ Planetary Science Institute, Tucson, AZ 85719, USA

${ }^{17}$ Malin Space Science Systems, San Diego, CA 92121, USA.

${ }^{18}$ Department of Physics, University of Guelph, Guelph, ON N1G 2W1, Canada.

${ }^{19}$ Space Remote Sensing, Los Alamos National Laboratory, Los Alamos, NM 87544 USA.

${ }^{20}$ Institut de Recherche en Astrophysique et Planétologie (IRAP), Université de Toulouse/CNRS, 31400 Toulouse, France.

${ }^{21}$ Center for Earth and Planetary Studies, National Air and Space Museum, Smithsonian Institution, Washington, DC 20560, USA

${ }^{22}$ Department of Earth and Planetary Sciences, Washington University in St. Louis, St. Louis, MO 63130, USA.

${ }^{23}$ Department of Earth and Space Sciences, University of Washington, Seattle, WA 98195, USA.

${ }^{24}$ U.S. Geological Survey, Flagstaff, AZ 86001, USA.

${ }^{25}$ Department of Earth and Planetary Science, University of California, Berkeley, CA 94720 , USA.

${ }^{26}$ Laboratoire de Geologié de Lyon, Université de Lyon, 69364 Lyon, France.

${ }^{27}$ Department of Geological Sciences, University of Texas at Austin, Austin, TX 78712, USA.

${ }^{28}$ School of Science, Rensselaer Polytechnic Institute, Troy, NY 12180, USA.

${ }^{29}$ Canadian Space Agency, St-Hubert, QC, J3Y 8 Y9

${ }^{30}$ NASA Headquarters, Washington, DC 20546, USA.

${ }^{31}$ Institute of Meteoritics, University of New Mexico, Albuquerque, NM, 87131 USA

${ }^{32}$ Department of Geology and Geophysics, University of Hawaii at Manoa, Honolulu, HI 96822 , USA.

${ }^{33}$ Department of Earth Sciences, Brock University, St. Catharines, Ontario, Canada, L2S 3A1

${ }^{34}$ Department of Astronomy, Cornell University, Ithaca, NY 14853, USA.

${ }^{35}$ Geophysical Laboratory, Carnegie Institution for Science, Washington, DC 20015, USA.

${ }^{36}$ Department of Earth and Planetary Science, Massachusetts Institute of Technology, Cambridge, MA 02139, USA.

${ }^{37}$ Lunar and Planetary Institute, Houston, TX 77058, USA.

$\dagger$ Present address: Department of Earth and Planetary Sciences, University of California, Santa Cruz, CA 95064, USA

$\S$ MSL Science team and affiliations are listed in the supplementary materials

*Correspondence to: grotz@gps.caltech.edu. 


\begin{abstract}
The Curiosity rover discovered fine-grained sedimentary rocks, inferred to represent an ancient lake, preserve evidence of an environment that would have been suited to support a Martian biosphere founded on chemolithoautotrophy. This aqueous environment was characterized by neutral $\mathrm{pH}$, low salinity, and variable redox states of both iron and sulfur species. C, H, O, S, N, and P were measured directly as key biogenic elements, and by inference $\mathrm{N}$ and $\mathrm{P}$ are assumed to have been available. The environment likely had a minimum duration of hundreds to tens of thousands of years. These results highlight the biological viability of fluvial-lacustrine environments in the post-Noachian history of Mars.
\end{abstract}

\title{
Introduction
}

The environmental history of early Mars is mostly written in stone. The first few billion years of Mars' geologic history records surface environments considerably different than the surface today, prompting a succession of coordinated surface and orbiter missions over the past two decades aimed ultimately at determining if Mars ever had an early biosphere. Water is the sine qua non for all life as we understand it and, therefore, past missions have sought environments where water was abundant and possibly long-lived. However, to create an environment that could have been habitable by microorganisms the presence of water alone is insufficient: a source of energy to fuel microbial metabolism, as well as the elements carbon, hydrogen, sulfur, nitrogen, and phosphorous (and a host of others at trace levels) also are required. The Mars Science Laboratory (MSL) rover Curiosity was designed and built to explore for these materials and thus potentially delineate one or more habitable environments at the Gale crater landing site. We show here that Gale crater once contained an ancient lake that would have been well suited to support a Martian biosphere founded on chemolithoautotrophy.

Exploration for habitable environments is Curiosity's core mission objective. Achieving this goal necessitates a challenging set of science measurements on just the right rocks to extend beyond the search for aqueous environments. To enhance the probability of mission success, we adopted an exploration strategy that included well-defined secondary objectives in addition to exploring Gale's central mountain, Aeolis Mons (informally known as Mt. Sharp), the mission's primary science target. The selection of the Gale crater field site, where Curiosity landed on August 6 $6^{\text {th }}, 2012$, UTC, was based on the recognition that it retained records of multiple and diverse ancient aqueous environments and thus enhanced the potential that one or more of those settings might have provided the combination of factors necessary to sustain a habitable environment (1). Another important factor included mapping the landing ellipse ahead of landing so that no matter where the rover touched down, our first drive would take us in the direction of a science target deemed to have the greatest value as weighed against longer term objectives, and the risk of mobility failure.

\section{Mapping and Geologic Framework for Exploration}


Gale crater is $154 \mathrm{~km}$ in diameter with a central mountain of stratified rock. Gale straddles the crustal dichotomy boundary, a topographic demarcation between heavily cratered uplands and sparsely cratered lowlands. In the vicinity of Gale the dichotomy boundary is crossed by numerous incised valley networks suggestive of surface aqueous flows that discharged to the north across the lowlands (2). Gale' s stratigraphy, mineralogy, and landforms have been well studied from orbit (3-6). A broader context for understanding Mt. Sharp has been developed (7) along with Gale's relevance to MSL's goals $(1,8)$. The primary mission objective is to examine the lower foothills of Mt. Sharp (Fig. 1a), located outside of the landing ellipse, where hematitic and hydrated clay-, and sulfate-bearing strata were detected from orbit $(5,9)$ and are accessible by the rover (1).

The surface mission was planned in advance (1) to take into account the drive distance from anywhere in the landing ellipse up to and across the Mt. Sharp foothills, including time for sampling and analyses en route. The landing ellipse is located in the broad valley (Aeolis Palus) between the Gale crater rim and Mt. Sharp (Fig. 1a). Depending on where Curiosity touched down, potential secondary science targets within the landing ellipse included the Peace Vallis alluvial (water deposited) fan lobe, a high thermal inertia terrain localized downslope from and adjacent to the fan, several fresh craters, and inverted stream channels. In the case of the current study, a secondary target near the landing site became a notable objective, with the decision (10) made after landing to drive in the opposite direction of the Mt. Sharp entry point to sample stratified rocks of relatively high thermal inertia exposed at Yellowknife Bay (11) (Fig. 1a, Fig. 2a).

Geologic mapping (12) building on earlier efforts (4) proved critically important to selecting the post-landing drive direction and science targets. This work provided the broader context in which to understand the strata drilled by Curiosity in Yellowknife Bay. The MSL team-generated map (Fig. 1b) reveals six units (13) that are distinguished based on variations in thermal inertia, textural attributes such as presence of scarps and lineations consistent with bedding, surface roughness based on shadowing, apparent relative albedo, and patterns of albedo variation such as those indicating fractures, bedding, or mottling. These units include: the Peace Vallis alluvial fan ("AF"); an immediately adjacent and downslope light-toned, bedded, fractured unit ("BF"); surfaces with relatively high crater densities ("CS"); tonally smooth but hummocky plains ("HP"); light-toned topographically variable, or rugged terrain ("RT"); and light-toned striated rocks ("SR"). By Sol 440 the RT and SR units had not been examined by Curiosity and are not discussed further. Both are considered as exposures of bedrock based on textures and higher thermal inertia values. The CS unit was inspected only from a distance during the traverses to and from Yellowknife Bay and likely reflects lateral equivalents of bedrock studied by Curiosity, discussed further below.

The HP unit is exposed in the vicinity of Bradbury Landing (14) and has lower values of thermal inertia. It is composed dominantly of loose materials including clasts interpreted to be impact ejecta, but also displays erosional remnants of underlying bedrock. Analyzed clasts have basaltic, alkalic (K and $\mathrm{Na}$ rich) compositions (15) and some clasts and soils contain crystals of probable feldspar (16). Windows through this material in the vicinity of 
Bradbury Landing, including the excavation zones produced by Curiosity's descent rockets, expose pebble conglomerate bedrock of fluvial (stream-related) origin (17).

The $\mathrm{AF}$ and $\mathrm{BF}$ units are important because of their intimate spatial association and possible relationship to rocks exposed at Yellowknife Bay. The AF unit is defined by the Peace Vallis fan which extends from the northwest rim of Gale crater (Fig. 1b); it may be the youngest component of a much more extensive alluvial plain that flanks the crater wall (4). The Peace Vallis fan likely formed by routing of eroded crater rim-derived rock fragments, and any materials that accumulated there after crater formation, through Peace Vallis followed by downstream spreading and deceleration of flows and deposition of sediments in the downslope direction. The upslope part of the AF unit is marked by smooth mottled surfaces punctuated by slope-aligned linear ridges with a relief of 0.5-2.5 $m$ interpreted as inverted stream channels. Downslope this unit passes into the widespread BF unit that continues all the way to Yellowknife Bay where it is coincident with the stratified bedrock exposed there, and the terrain that marks the floor of the "bay" (18) itself. Although map relationships suggest that the BF unit represents distal fan facies (rock types), they do not require that the Yellowknife Bay BF exposures are contemporaneous with the Peace Vallis lobe of the alluvial plain; they could represent an older component of the alluvial plain, separated from the youngest activity by an unconformity (see below). Nevertheless, the close spatial association implies a genetic link, with the BF unit having formed in a probably distal alluvial or even lacustrine (lakerelated) setting, consistent with earlier mapping (4).

Geologic units in the interior of Gale crater display a range of relative ages and preserve a substantial record of geologic activity since the crater formed close to the Noachian/Early Hesperian boundary, approximately at 3.7 Ga (6). The oldest units probably are of Early Hesperian age and likely include the bulk of the alluvial plain that extends downslope of the crater rim. The Peace Vallis alluvial lobe (map unit "AF") appears to represent the latest stage of transport and deposition on the alluvial plain.

Our mapping shows that strata exposed at Yellowknife Bay are likely fan, distal fan, or downslope equivalents such as lacustrine deposits. Despite the ambiguity in the relative age of these strata, the fluvial-lacustrine depositional context remains intact and this is what motivated the MSL science team to explore these rocks.

\section{Stratigraphy and Sedimentology of Yellowknife Bay Rocks}

Bradbury Landing occurs near the crest of a broad topographic high, several $\mathrm{km}$ in width, informally called Bradbury Rise. To the north and east the rise descends to rocks of the BF unit. After landing, the team-consensus decision was to traverse eastward, and downhill, to the HP-BF contact, as close as possible to the triple junction where the CS unit also intersects (Fig. 1b). Between Bradbury Landing and Yellowknife Bay Curiosity crossed a straight-line distance of 445 meters and descended 18 meters in elevation. Most of this distance was spent traversing the clast-strewn HP unit, with its occasional outcrops of pebble conglomerate facies. Beginning at the Bathurst Inlet outcrop, a succession of strata 
was encountered with good exposure down to the floor of Yellowknife Bay (Fig. 2a). In ascending order these strata are informally named the Sheepbed ( $>1.5 \mathrm{~m}$ thick), Gillespie Lake ( $\sim 2.0$ meters thick), and Glenelg members ( $\sim 1.7$ meters thick); the assemblage of members is known as the Yellowknife Bay formation, and the exposed section is approximately 5.2 meters thick. (Fig. 3, table S1). Strata are largely decimeter-scale in thickness and comprise a heterogeneous assemblage of mostly detrital sedimentary rocks of basaltic bulk composition. Breaks in outcrop continuity due to accumulated loose materials on the slope (Fig. 3) introduce a degree of uncertainty in understanding lateral extent of bedding; the lowest stratigraphic members (Sheepbed and Gillespie Lake) are best exposed around the perimeter of Yellowknife Bay (Fig. 2b). The Glenelg member contains a diverse suite of facies formed of beds with demonstrably less lateral continuity although most beds can be traced for at least tens of meters.

The basal Sheepbed and Gillespie Lake members are characterized (19) by elemental compositions broadly consistent with a provenance that, on average, is similar to typical Martian upper crust (20). In addition, these rocks carry the signal of higher thermal inertia as seen from orbit. Subtle geochemical variations within and between these units mostly reflect minor variations in provenance. A striking change in composition takes place higher in the section in the Glenelg member (Bathurst Inlet outcrop), best reflected by a sharp increase in $\mathrm{K}_{2} \mathrm{O}$ contents and $\mathrm{K}_{2} \mathrm{O} / \mathrm{Al}_{2} \mathrm{O}_{3}$ ratios (Fig. 4), suggesting a fundamental change in the provenance to one dominated by more alkaline igneous rocks $(16,21)$. This change could result from either propagation of the fluvial system headwaters into an area with more alkaline igneous rocks or a shift to more locally derived volcanic debris, such as reworked volcanic rocks or ash deposits (21). Major element compositions do not indicate substantial chemical weathering in the sediment source area, which implicates either a frigid or arid climate, or a high relief source area undergoing rapid erosion, or a combination of these factors $(19,21)$.

In general, the Yellowknife Bay formation (Fig. 4) is composed of fine, medium, and coarsegrained sandstones of basaltic composition. The Shaler outcrop ( $\sim 125 \mathrm{~cm}$ thick) consists of a heterogeneous assemblage of interstratified platy coarser-grained beds comprising sandstones and likely pebbly units, separated by recessive, probably finer-grained intervals. Coarser-grained intervals are characterized by distinct decimeter scale trough cross-bedding (Fig. 5a). Recessive intervals are marked by downward-tapering cracks that terminate upward at bedding planes and are likely filled with sediment from the overlying bed. The rock "Rocknest-3" is very fine grained, finely laminated sandstone or siltstone with shrinkage cracks (Fig. 5b). Volcanic or impact related base-surge deposition is excluded by the abundance of decimeter-scale and compound cross-bedding; absence of stoss-side cross-stratification with preservation only of bedform toesets; and variable cross-bed dip directions. Furthermore, there are hierarchical scales of cross-stratification at the Shaler outcrop, indicating migration of superimposed bedforms of different scales. These attributes are most consistent with a former fluvial environment characterized by bedload and suspended load transport and variable, but net southeast flow directions. However, some eolian bedload transport is suggested by intercalated beds with pinstripe lamination. Most paleocurrent data are restricted to 90 degrees of variability (fig. S1), however, some scatter to almost 180 degrees which is consistent with migration of three- 
dimensional superimposed bedforms (22). The inferred sediment transport direction suggests derivation of sediments from the direction of the Gale crater rim. A fluvial interpretation is further supported by the tapered, likely sediment-filled cracks that are most easily accounted for by desiccation-induced shrinkage of finer-grained interbeds. These interbeds could represent either fluvial overbank deposits, slack water deposits in the troughs between bedform crests, or intercalated tongues of proximal lacustrine facies.

The Point Lake outcrop ( $~ 50$ centimeters thick) is noteworthy for its pervasive cm-scale voids (Fig. 5c). These voids could possibly point to a volcanic origin, specifically a vesicular lava flow (23). Alternatively, it is possible that this facies also represents a pebbly debris flow or gas-charged intrusive sedimentary sill $(24,25)$. Scattered blebs of light toned material were evaluated as calcium sulfate by ChemCam (19) and appear to fill voids and narrow fractures. Thus, it is possible that the rock could be a sandstone with leached nodular evaporites (26).

The Sheepbed and stratigraphically overlying Gillespie Lake members (Fig. 3, Fig. 4) comprise the exposed base of the Yellowknife Bay formation and their contact has eroded to form a decimeter-scale distinctive topographic step observable in HiRISE orbiter image data (Fig. 2a). The Gillespie Lake member consists of amalgamated, sheet-like sandstones. Bedding generally has a massive appearance though poorly-defined cross-bedding is present. The basal bed of the Gillespie Lake member is formed of poorly sorted, angular to moderately well rounded, medium to very coarse sand of bulk basaltic composition (Fig. 5d). Some of the largest grains have translucent luster. Very little residual porosity between grains is evident suggesting a high degree of cementation; what porosity does exist appears as sparse, mm-scale irregular vugs (void spaces). This basal bed has a sharp, erosional base that shows cm-scale scouring into the underlying Sheepbed member mudstones, and appears to show lateral variation in its thickness. The poor sorting, massive bedding and variability of grain shape in the Gillespie Lake sandstones are most consistent with fluvial transport and deposition. The sheet-like geometry of the beds extending over hundreds of meters, and absence of well-developed channel bodies may indicate deposition as distal fan lobes, as documented in examples from ancient alluvial fans on Earth (27).

The pebble conglomerate outcrops distributed across the HP map unit have an uncertain stratigraphic relationship with respect to the Yellowknife Bay formation. On one hand, the conglomerate exposures occur at a topographically high level above flat-lying rocks of the Yellowknife Bay formation; the simplest interpretation would invoke superposition and therefore a younger age for the conglomerate than the Yellowknife Bay formation. However, regional mapping allows for, but does not require, an alternative possibility in which flat-lying Yellowknife Bay rocks unconformably onlap older rocks that underlie the HP map unit; in this interpretation the conglomerate is relatively older. Unfortunately, outcrop between Yellowknife Bay rocks and the nearest conglomerate is very poor, and it is not possible to observe a contact. Therefore, either option is possible but in either case these rocks all belong to the same genetically related suite of fluvial-lacustrine sediments derived from the crater rim. 


\section{Sheepbed Mudstone member}

At a minimum, the Sheepbed member extends laterally across the width of the outcrop belt traversed by the rover - approximately 60 meters. The Sheepbed member closely coincides with the BF map unit, and from orbit is highlighted by its light tone and extensive meter- to decameter-scale fracture network. Tracing of the distinctive erosional profile of the Sheepbed-Gillespie Lake contact shows that the Sheepbed member likely extends around the full width of Yellowknife Bay and covers a minimum area of about 4 square kilometers. However, we presume the Sheepbed member extends beneath the overlying rocks of the Gillepsie Lake member, and therefore these are highly conservative minimum estimates. A reference section localized near the Selwyn target (Fig. 3) yields a thickness of 1.5 meters for the member. This is a minimum thickness because its base is not exposed.

A detailed traverse (Selwyn reference section) using Mastcam, ChemCam, APXS, and MAHLI measurements was conducted across the Sheepbed member for the purpose of providing context for the first samples obtained by drilling (Fig. 3, Fig. 4). Observations revealed a patchy distribution of diagenetic (post-depositional) features, including nodules and veins, discussed below. Mineralogic data show that the Sheepbed member has a substantial quantity of saponitic smectite clay minerals $(\sim 20 \%)$, likely formed by aqueous alteration of olivine (28). Geochemical results (19) show that both Sheepbed and Gillespie sediments were derived from a provenance with a composition similar to average Martian crust, and which experienced negligible chemical weathering before deposition at Yellowknife Bay. Relatively subtle differences exist between lower and upper parts of the Sheepbed, such that the top exhibits higher $\mathrm{Al}_{2} \mathrm{O}_{3} / \mathrm{TiO}_{2}$ and $\mathrm{Ni}$, consistent with a slight provenance change. A further change in trace elements (higher $\mathrm{Cr}$, lower $\mathrm{Ni}, \mathrm{Ge}$ ) occurs across the Sheepbed Gillespie Lake contact that could result either from provenance differences or mineral sorting (e.g., chromite) associated with grain size differences. Both APXS measurements and high spatial resolution ChemCam targeted analyses provide evidence that crosscutting veins and fractures are composed of Ca-sulfate (see below).

Highest resolution MAHLI images were acquired on Sol 150 (Ekwir) and on Sol 169 (Wernecke) following brushing of the outcrop (Fig. 5e). These images reveal a very fine grain size based on the outlines of darker grains and nearly all discernable grains are finer than $50 \mu \mathrm{m}$. By definition, a mudstone is a fine-grained sedimentary rock composed of $50 \%$ or more particles smaller than $62 \mu \mathrm{m}(29)$. Although we cannot directly resolve and observe these $<50 \mu \mathrm{m}$ grains, we do know that $\sim 20 \%$ are clays. It seems likely that the entire Sheepbed member is finer than most facies observed by Curiosity during the traverse down to Yellowknife Bay. Drilling of the outcrop produces gray powder and cuttings, substantially different in color from the modern surface (Fig. 5f). Inspection of the drill hole reveals a gray rock that is fine-grained and homogeneous in texture, with the exception of light-toned mineral-filled fractures.

Independent evidence for the fine grain size of the Sheepbed mudstone comes from inferences of the physical responses of brushing and measurements made during drilling. The rotary motion of bristles during brushing substantially scored the surface of the outcrop in a fashion that shows deflections (Fig. 5e) around apparently harder, embedded dark nodules suggesting the mudstone matrix is softer. Comparison with terrestrial analog 
data suggests weak/medium hardness for the mudstone (30). Additional estimates of rock hardness are provided by comparison of rover engineering testbed data derived from terrestrial analogs with drill hardness data from the Sheepbed member (31). These datasets suggest the Sheepbed rock is comparable to fluvial to lacustrine siltstones/mudstones collected from the 10 million year-old Ridge Basin of southern California (buried to depths of several $\mathrm{km}$ ) but not as hard as feldspathic sandstones derived from the same basin, or as soft as pure commercially available kaolinite.

Sheepbed mudstones contain a few very thin intercalated beds that resist erosion (Fig. 4). These interbeds have not been studied in detail, but Mastcam data show them to be $1-2 \mathrm{~cm}$ thick and with substantial lateral continuity as some can be traced for $>100$ meters. Overall the primary texture and grain size has a very uniform, massive appearance; it is well known, however, that lamination can be difficult to detect in many mudstones (29).

The very fine grain size, its apparently uniform distribution through the member, and the substantial lateral extent of $\mathrm{cm}$-scale interbeds are all consistent with deposition of the primary grains due to settling from suspension, either from the atmosphere or a water column. The former might involve volcanic ash, eolian dust, or very distal impact fallout. Because the composition of the Sheepbed mudstone is basaltic and we cannot ascertain the very finest grain sizes, it is hard to discount an airfall origin. However, mapping relationships, regional context, and local sedimentologic constraints all point to a distal alluvial fan or proximal lacustrine setting. In this setting, sediment-laden fluvial flows can deposit extensive fine-grained deposits either as overbank flood deposits or at their downstream termination where they enter a body of standing water, such as a lake. Here, the decrease in flow turbulence as flows thin overbank and spread when leaving a channel, or encounter the still water of a lake, leads to deposition of suspended fines. We favor the lake interpretation because of the lateral extent and thickness of the Sheepbed member, the absence of fluvial channel bodies laterally adjacent to mudstone beds, and the fact that the mudstone underlies the Gillespie Lake member fluvial sheet sandstones over a large areal extent. Given our limited observations it is difficult to exclude the hypothesis that this lake may have been seasonally dry (playa), or if it responded to longer-term wet/dry climatic fluctuations. However, the compositional data favoring low salinity for the lake waters (19) and specific diagenetic textures discussed below (cement-filled synaeresis cracks, rather than sediment desiccation cracks) suggest that it was perennially wet for the stratigraphic interval that we examined.

Strata dominated by fluvial sediments that predate the advent of terrestrial vegetation on Earth are generally devoid of fines except as occasional mud drapes that are preserved between sets of cross-stratified dune or bar deposits $(32,33)$. Sweeping of very broad and shallow channels that produce sheet flood deposits result in reworking of thin floodplain deposits that tend to not be preserved in the stratigraphic record. In addition, eolian reworking between flow events - in the absence of terrestrial vegetation to anchor fines is also regarded as an efficient mechanism to sweep fines away from sites of deposition. Thus, a shallow lacustrine environment, which sequesters fine sediments over long time scales, is considered to be the most likely interpretation for the Sheepbed mudstone. 
The grain size and composition may be inconsistent with typical Mars dust, which is even finer in grain size and characterized by $\mathrm{SO}_{3}$ contents approaching $7 \%(20,34)$ rather than the Sheepbed mudstone which is closer to $1 \% \mathrm{SO}_{3}(19)$. Although it seems conceptually possible to deposit relatively thick intervals of dust $(35,36)$ this might not be expected on an alluvial fan that is intermittently active enough to result in the substantial amounts of coarser-grained sediment accumulation seen in the Yellowknife Bay formation.

Furthermore, estimates of dust accumulation rates are very low (on the order of $10 \mathrm{~cm} / \mathrm{My}$ (37)) as compared to fluvial or even lacustrine sediment accumulation rates which are orders of magnitude higher (38).

Sheepbed compositions likely discount an origin as pure volcanic ash. Apart from variation imposed by sulfate-rich diagenetic features, the Sheepbed is geochemically uniform with an adjusted volatile-free composition close to average Martian crust (19). Individual volcanic ash eruptions might be expected to display some variation in composition and it would be coincidental for individual eruptions to all have a composition essentially the same as the average crust. If the $>1.5 \mathrm{~m}$ thick Sheepbed member represented a single eruption this would require a local source that is not observed in the vicinity of Gale crater (likely within a few tens of $\mathrm{km}$ for $1 \mathrm{~m}$ thickness (39)).

\section{Diagenesis of the Sheepbed Mudstone}

A diverse set of diagenetic features that postdate deposition is observed in the Sheepbed mudstone member. Early diagenetic features include "nodules", "hollow nodules", and "raised ridges" (Figs. 6a-c). These features are crosscut by later fractures, filled with lighttoned cements (Fig. 6d) shown to be variably hydrated sulfate minerals based on ChemCam, APXS, Mastcam and CheMin data. Additionally, a dike-like feature, known as the "snake" obliquely crosscuts the Sheepbed-Gillespie Lake contact and extends for several meters (Fig. 3).

Concentrations of nodules and hollow nodules have patchy distributions and pass laterally (Fig. 7) into mudstones that have raised ridges. Nodules are expressed as mm-scale protrusions of the outcrop with three-dimensional differential relief suggesting crudely spherical geometry (Fig. 6a). The mean diameter of 4501 nodules is $1.2 \mathrm{~mm}$, with minimum/maximum diameters of $0.4 / 8.2 \mathrm{~mm}$. Brushing shows that nodules are more resistant to brush-induced etching, and thus harder, than the surrounding mudstone (Fig. 5e). Mastcam, MAHLI and ChemCam Remote Micro-Imager (RMI) data show that nodules are dispersed from one another, cluster in patches (Fig. 7), do not form their own beds, and show no evidence of size grading despite a broad range in diameters. These constraints suggest that the nodules are of concretionary origin rather than volcanic or impact lapilli $(40,41)$. Furthermore, no associated outsized clasts that might be interpreted as potential bombs, or any breccias are observed. Comparison of John Klein (fewer nodules and hollow nodules) and Cumberland (more nodules and hollow nodules) compositional data indicates that nodule and hollow nodule rim growth may have involved iron-bearing compounds such as the mineral akaganeite or even clay minerals $(19,28)$. 
Hollow nodules are mm-scale circular rims with hollow centers (Fig. 6b). Threedimensional exposures sometimes reveal pedestal-like structures with a circular rim surrounding a hollow, bowl-like depression. The outcrop therefore has a locally pitted appearance, suggesting erosional exposure of approximately spherical voids that had resistant rims, similar to the nodules. Resistance to weathering by the rims of the hollow nodules is indicated by the presence of lineations and "wind tails" carved into the outcrop, presumably by eolian saltation abrasion. Development of pedestals likely records lowering of the outcrop surface by prolonged eolian abrasion. Mastcam, MAHLI and ChemCam RMI data show that hollow nodules are similar in size to nodules with mean diameters of 1.2 $\mathrm{mm}$, and minimum/maximum diameters of $0.6 / 5.6 \mathrm{~mm}(\mathrm{n}=1248)$. We note that the upper size limit of hollow nodules is considerably smaller than that for nodules. The interior mean diameter of the void space defining the "hollow" is $0.7 \mathrm{~mm}(\mathrm{n}=45)$.

Hollow nodules are regarded as void spaces preserved within the Sheepbed mudstone. However, the hollow nodules are distinctly different from mm-scale diagenetic vugs, such as in the Gillespie Lake member or Burns formation of Meridiani Planum (40), in that the hollow nodules are associated with a ubiquitous circumscribed rim. Spherical voids of this type have not been observed previously on Mars, and perhaps relate to their ability to be preserved - in this case within fine mudstone sediments. Two options are possible to explain the void space, which creates the hollow observed in outcrop. In the first hypothesis the void space would represent a vanished mineral, whose higher solubility allowed easy dissolution during subsequent diagenetic fluid percolation events. Such minerals might have grown displacively in the sediment, for example, in evaporites (26), thereby eliminating the need for the void to have been primary. However, no examples of filled hollow nodules were observed, with one very specific exception: where hairline fractures filled with light toned sulfate minerals intersect hollow nodules then the hollow nodules also are filled with sulfates. Otherwise hollow nodules are devoid of any remnant of an earlier mineral. The sulfate-filled fractures represent a later phase of diagenesis (see below) and therefore the sulfate minerals are not considered part of the primary environment.

This allows for a second hypothesis in which the hollow nodules represent primary voids, such as gas bubbles formed during or soon after deposition. Several mechanisms could generate gas during or after sedimentation including diagenetic dissolution/precipitation reactions that might produce gas as a byproduct. These might include hydrogen gas produced during authigenic clay mineral formation via olivine "saponitization"(28); UV photo-oxidation of reduced minerals such as siderite to produce authigenic iron oxide (e.g. magnetite) and hydrogen gas (42); pressure-induced release of dissolved gas from sedimentary pore fluids; and processes that reflect unique Mars environments such as boiling of water in the presence of critically low atmospheric water vapor pressure. Data are insufficient to distinguish among these possibilities. However, the last of these can be discounted by the presence of thin interbeds within the Sheepbed mudstone, which suggest that wholesale churning of the mudstone did not occur. A final possibility considers the potential role of microbes, if life had ever evolved on Mars. Terrestrial sediments are pervaded by microbes, which produce a variety of gases that become trapped as bubbles where lithification is early and rapid (43). However, it should be clear enough that this 
mechanism can only be invoked as a serious possibility after all other abiotic hypotheses have been discounted. This is not the case for our current data set and we include this only for the sake of completeness.

Raised ridges (44) are narrow, curvilinear ridges that weather in raised relief and, as mentioned above, they substitute laterally for nodules and hollow nodules (Fig. 7). The raised ridges are restricted to the Sheepbed mudstone but one poorly constrained example was noted at a higher stratigraphic level (observed only from a distance; exact stratigraphic position and facies are uncertain). Measurement of 1619 raised ridges in the Sheepbed suggests they extend at least several centimeters in length and have a mean width of $2.7 \mathrm{~mm}$, with maximum widths of up to $5.8 \mathrm{~mm}$. Raised ridges have spindleshaped, pointed terminations (Fig. 6c). Most have subvertical orientation, but can dip more gently, down to 45 degrees or less, and their strike trends in all directions (Fig. 6c). Ninetydegree intersections between ridges are common. A distinctive attribute is that most ridges show internal banding which contours the trend of the ridge, following closely all local deviations including right-angle bends. Two parallel bands are most common, although three to four are also observed (Fig. 6c). Raised ridges are most simply interpreted as early diagenetic cracks that formed in consolidated or even partly lithified mudstone, then filled with one or more generations of cement that isopachously encrust the margins of the cracks. This infilling material has greater resistance to eolian erosion than the mudstone resulting in its expression as ridges. ChemCam and APXS analyses have identified elevated $\mathrm{Mg}, \mathrm{Fe}, \mathrm{Si}, \mathrm{Cl}, \mathrm{Li}$ and $\mathrm{Br}$ in the raised ridges but insufficient evidence exists to confidently identify specific mineral phases (19). A strong correlation exists between $\mathrm{Mg}$, Fe and $\mathrm{Cl}$ possibly indicating a chloride phase may be present, but if so, it can only explain a small amount of the $\mathrm{Mg}$ and Fe enrichment. Alternatively, the correlation could result from a phase other than a chloride that contains substantial Cl. For example, CheMin data suggest the presence of akaganeite (28).

Taken alone, the development of very early cracks in fluvial to lacustrine mudstones might be most simply explained by desiccation of wet sediment and, generally, desiccation cracks have polygonal geometry. Therefore, the non-polygonal geometry of the cracks is unexpected, as is the isopachous, banded materials that fill in the fractures. Furthermore, the abundance of raised ridges is anti-correlated with the abundance of nodules/hollow nodules, suggesting that all three phenomena are genetically related, which is not something that is observed for desiccation cracks on Earth. An alternative mechanism would postulate that syn-depositional pore fluids (perhaps mixing with surface runoff waters) may have been important in driving diagenetic reactions that triggered early mineral precipitation, gas production, and volume contraction close to the sediment-water interface. On Earth, a related but poorly understood process known as "synaeresis" is thought to relate to clay mineral flocculation during mixing of saline and less saline waters, resulting in differential contraction of the substrate (45). Seismic shaking, perhaps induced by impacts on Mars, may help facilitate this process (46). The result is spindle-shaped cracks, a few centimeters long that look very much like the Sheepbed raised ridges. In most cases on Earth, the cracks are filled by other sediments, however, in one very particular instance known as "molar tooth structure" spindle-shaped cracks and related subspherical voids are filled with mineral (calcite) cement. The origin of subaqueous cracks on Earth is 
poorly understood, though the involvement of gas in generating the cracks and voids represented by molar tooth structure is likely $(43,47)$. As with the hollow nodules, a number of processes could generate gases in Martian sediments. In general the distribution of subaqueous shrinkage cracks reflects differential strength of the substrate materials, which may similarly be represented in the Sheepbed member by the spatial segregation of the nodules/hollow nodules versus raised ridges.

A unique feature within lower Yellowknife Bay strata is a dike-like, dark-toned rock unit referred to as the "snake", named after the target "Snake River" (see Fig. 3). This feature extends from the lowest stratigraphic level of the exposed Sheepbed member, crosscuts the Sheepbed-Gillespie Lake contact, and tapers out within the middle of the overlying Gillespie Lake member (Fig. 3, Fig. 4). The "snake" is $6-10 \mathrm{~cm}$ wide and can be traced across bedding for about 5 meters, cutting up through almost $1 \mathrm{~m}$ of stratigraphic section. MAHLI images of unbrushed parts of the snake suggest it has a fine-grained clastic texture, but with larger fragments present suggestive of intraclasts (fig. S2). Elemental data show it to be similar in major elements but distinct from the Sheepbed member in trace element abundances (19). The "snake" can be traced to its stratigraphically highest position where it terminates in a small anticline. At this terminus thicker, massive beds extend laterally away from the core of the anticline. The "snake" has several possible interpretations including a narrow igneous dike of basaltic composition; a large-scale crack that is filled from above, perhaps associated with subaerial exposure or ice wedging; or a sedimentary intrusion associated with compaction and dewatering of the mudstone or subjacent strata.

The fine-grained, basaltic composition of the "snake" makes it hard to exclude an igneous intrusion with basaltic composition. The feature is so thin that grain-size variations consistent with chilled margins would be unexpected at scales within MAHLI's limit of resolution; the entire dike would be expected to be very fine grained. Filling from above is discounted due to the presence of the small anticline, which suggests injection of fluidized material from below rather than settling of sediment from above. In addition, no evidence of layering - suggestive of downward percolation of sediments - is observed within the feature. Furthermore, no other crack-like features are observed to extend downward from a common stratigraphic surface. The third possibility - intrusion of plastically-deformed sedimentary materials - occurs in some sedimentary environments with high sedimentation rates $(24,25,48,49)$. Upward and lateral injection of compacting muds and sands is most commonly expressed as dikes and sills that both crosscut strata and intrude along bedding planes. The similarity of both composition and texture to that of the Sheepbed mudstone, the presence of possible intraclasts, and upward deflection of strata at its terminus are all consistent with sedimentary injection $(24,25)$. This suggests a sediment accumulation rate for the Yellowknife Bay formation (or sediments below it) that was high enough so that pore fluid pressures built up to the point where expulsion along discrete zones of weakness, rather than along grain boundaries, was the preferred pathway for escape of compacting sediments and interstitial pore fluids. As the porosity and permeability of the sediment was reduced via compaction and cementation, the strata may have ruptured allowing fluids to escape and form sedimentary dikes and sills. Finally, this process could have been aided by impact-induced seismic activity (50). 
Fractures filled with light-toned sulfate cements also are regarded to have formed later in the diagenetic sequence because they cut the entire Yellowknife Bay formation. In contrast to the raised ridges, the sulfate-filled fractures are flush, even slightly depressed, with respect to adjacent unfractured outcrop (Fig. 6, Fig. 7). Sulfate-filled fractures have highly diverse orientations spanning from vertical to sub-horizontal, range in length from less than $1 \mathrm{~cm}$ to over $30 \mathrm{~cm}$, and range in width from "hairline" (sub $\mathrm{mm}$ ) to $8 \mathrm{~mm}$, with a mean width of $2.3 \mathrm{~mm}$ (Fig. 5e, Fig. 6d). MAHLI images of the John Klein drill hole show that hairline-width sulfate-filled fractures have complex orientations with horizontal as well as vertical trends (Fig. 5f). Where these hairline-width fractures intersect hollow nodule void spaces (Fig. 5e), the latter also are filled with hydrated as well as anhydrous calcium sulfate minerals as determined by CheMin, ChemCam, and APXS data $(19,28)$. At a larger scale, the observation of fracture-filling hydrated sulfate mineralogy can be extended through Mastcam observations. Calibrated Mastcam spectra show evidence for hydration associated with most, but not all of the fracture fills, including limited hydration in hairline fractures that penetrate and fill the void space of hollow nodules (28).

To form, the sulfate-filled fractures first require lithification of the Sheepbed and Gillespie Lake members in order to allow applied stress to cause brittle strain of the bedrock (51). Once open, the fracture networks then act as conduits for fluid transport resulting in precipitation of cementing minerals within these initially low permeability sedimentary rocks. Possibly the fracture networks were created by hydraulic fracturing due to high fluid pressures that would have been obtained during burial of Yellowknife Bay strata (51). The variation in hydration state of vein-filling sulfate mineralogy between gypsum, bassinite, and anhydrite could reflect primary variations in environmental conditions during deposition or, alternatively, diagenesis associated with burial and/or desiccation during subsequent erosion and exposure (28).

A final observation regarding later diagenesis concerns the Gillespie Lake sandstone member, which shows evidence for possible secondary porosity. Irregular vugs larger than the diameter of the average grain size (Fig. 5d) suggest that larger grains, or perhaps clusters of grains, were leached during fluid circulation. Alternatively, it is possible that these vugs represent intraclasts of mudstone that degraded by weathering. Another possibility is dissolution of preferentially more soluble early diagenetic minerals; however, the irregular shape of the vugs is not consistent with dissolved evaporite crystals.

In summary, the diagenesis of the Sheepbed member suggests a complex aqueous history involving at least two distinctly different water masses. Following emplacement in distal alluvial to lacustrine environments, pore spaces in primary sediments were occluded by cements, and early diagenetic hollow nodule voids (gas bubbles?) may have been formed, along with concretions. At approximately the same, time non-polygonal fissures in the lithifying sediment opened up and became lined with void-filling isopachous rim cements. All these events, with the exception of hollow nodule void formation, must have occluded much of the primary porosity. This episode of diagenesis did not substantially change the bulk rock chemistry of these units relative to average Martian basalt and are thus considered to have involved isochemical alteration (19). This suggests that clay mineral and magnetite formation happened largely in situ, as a result of alteration of olivine to form 
authigenic saponitic smectite $(19,28)$. In addition to pore filling cement, it is possible that these minerals also precipitated as concretions as well as isopachous rim cements within raised ridge fractures. Following lithification, fracture porosity was created that was then filled with a distinctly different fluid that resulted in precipitation of sulfate cements (19, 28). The absence of elevated sulfate abundances in the Sheepbed mudstone, except for within these fractures, indicates that cementation and permeability reduction of the mudstone was extensive enough so that sulfate-rich fluids percolating through fractures and hairline fractures did not invade the mudstone or sandstone matrix $(19,28)$. The first diagenetic fluid, possibly derived from the waters that transported sediments, was dominated by dissolved silicate and iron oxide minerals. The second, subsequent fluid was dominated by sulfates and perhaps sampled a broader, basin-wide hydrologic system. CheMin and SAM data additionally point to a substantial X-ray amorphous fraction of material that could have been involved in diagenesis, as well as potential sulfide minerals $(28,52)$.

\section{Sheepbed Mudstone: Record of Habitable Environment}

The regional geologic context, sedimentologic framework, and geochemistry and mineralogy of the Sheepbed mudstone all point to an ancient environment that would have been habitable to a broad range of prokaryotic microorganisms. The relatively neutral $\mathrm{pH}$ indicated by clay mineral stability (28), high water activity indicated by low salinity for primary and early diagenetic environments (19), the variable redox states indicated by presence of magnetite, sulfate and sulfide minerals and compounds $(28,52)$, and the apparent long duration of the aqueous environment(s) all support this interpretation.

The Sheepbed mudstone closely coincides with the BF map unit (Fig. 1) suggesting that this rock unit may have extended beyond the confines of Yellowknife Bay and minimally covered an area of $\sim 30 \mathrm{~km}^{2}$, not including buried or eroded equivalents. Repeated flows of water (17) and the likely presence of a body of standing water point to a sustained habitable environment. The durations of the primary, early diagenetic, and later diagenetic aqueous environments were substantial enough to create geologic and geochemical fingerprints of prolonged fluvio-lacustrine and diagenetic processes remarkably similar to those that formed commonly during early Earth history $(32,53,54)$.

A rough estimate of the minimum duration of the lacustrine environment is provided by the minimum thickness of the Sheepbed member. Given 1.5 meters, and applying a mean sediment accumulation rate for lacustrine strata of $1 \mathrm{~m} / 1000$ yrs (38) yields a duration of 1,500 years. Lacustrine sediment accumulation rates vary by several orders of magnitude (38), thus the hypothesized lake could represent hundreds to tens of thousands of years. If the aqueous environments represented by overlying strata are considered, such as the Gillespie Lake and Glenelg members, then this duration increases. Indeed, the regional geologic context suggests that the Yellowknife Bay formation may be just a small part of a thick series of fluvio-lacustrine rocks that may exist in the subsurface for hundreds of meters. Moreover, it is possible that hundreds of meters of fluvial-lacustrine strata have been eroded. The sulfate-filled fractures are consistent with some amount of burial, and 
independent support for this is allowed (but not required) by possible incipient chloritization of mudstone smectite (28). Therefore, it is entirely plausible that, collectively, these hundreds of meters of strata could represent millions to tens of millions of years.

Episodic drying of this lake environment seems certain over this long time scale if not over shorter spans represented by thicknesses equivalent to the exposed Sheepbed mudstone. However, even if the lake was dry periodically, or if unconformities interrupted the continuity of fluvial-lacustrine sedimentation, the presence of former groundwater - well documented for many ancient Mars phenomena (55-57) - may have provided a refugium to sustain a chemolithotrophic biosphere. Episodic lake rejuvenation would permit a subsurface chemoautotrophic microbiota to emerge to the surface in response to a rise in groundwater level.

We can more specifically assess the habitability of the former environment represented by the Sheepbed mudstone from a perspective shaped by our knowledge of terrestrial biology. This approach involves identification of the chemical and physical environmental requirements that would support prokaryotic microbes, if similarly simple forms of life had ever evolved on Mars. Bacteria and archaea represent ancient, abundant and metabolically diverse domains of life on Earth and are able to withstand a wide range of environmental conditions (58-61). They can engage in a multitude of autotrophic and heterotrophic pathways, and utilize a variety of electron donor/acceptor pairs for acquisition of carbon and energy (62-65). We can envisage many combinations of terrestrial microbes that would be suited to form a Martian biosphere founded on chemolithoautotrophy at Yellowknife Bay.

As a first step it is useful to assess the key nutrients required to support terrestrial bacteria and archaea (66). The defining chemistry is inorganic: elemental inventory, liquid water, Eh, $\mathrm{pH}$, redox couples, and a diversity of chemical compounds. Organic molecules are not required environmental constituents because they can be synthesized de novo through the 'primitive' autotrophic pathways such as methanogenesis and acetogenesis (67). We have measured $\mathrm{H}, \mathrm{O}, \mathrm{S}, \mathrm{C}, \mathrm{N}$ and $\mathrm{P}$ in minerals and other compounds with the APXS, ChemCam, CheMin, and SAM instruments, as well as important metals such as Fe, Mg, and Mn (19, 28, 52). All but $P$ are observed in SAM EGA data as volatiles and all but $P$ and $N$ are known to be part of mineral structures observed in CheMin data. We do not have the capability to determine whether P would have been bioavailable, and CheMin observed no highly soluble P-bearing minerals. On the other hand, CheMin data indicate substantial breakdown of olivine in the mudstone at Cumberland (28) and $\mathrm{P}$ can be a trace to minor element in that mineral (68) suggesting potential P mobility during diagenesis. Nitrogenbearing compounds, in both reduced and oxidized forms, were measured by SAM during EGA (52). Evolved NO (m/z 30) has an abundance that is substantially above background, pointing to a likely source within the mudstone. Bio-available $\mathrm{N}$ conceivably could have been derived from the atmosphere via fixation by sulfide minerals during reactions similar to that seen in pyrrhotite, pyrite, and magnetite assemblages on Earth $(69,70)$.

SAM EGA data from John Klein show carbon to be present, either in crystalline (carbonate?) phases below $1 \%$ abundance, as a carbonate-bearing component in the X-ray amorphous 
material detected by CheMin, or derived from complex organic sources not detectable by SAM. Thus, most or all the major ingredients required to support life are present in the Sheepbed mudstone.

As a second step, we identify plausible redox couples represented by minerals and other compounds preserved in the Sheepbed mudstone that might have comprised basic energyyielding reactions for an elementary microbial community (66). The presence of both sulfur and iron is indicated by ChemCam, APXS, CheMin and SAM data. Further, observation of key inorganic volatiles such as $\mathrm{H}_{2} \mathrm{O}, \mathrm{H}_{2} \mathrm{~S}, \mathrm{SO}_{2}, \mathrm{H}_{2}$ and $\mathrm{CO}_{2}$, generated during $\mathrm{SAM}$ pyrolysis (52), suggests a wider range of redox conditions for the surface of ancient Mars than previously recognized based on Viking, Phoenix, and MER data (71-74). For example, SAM analysis of the John Klein sample shows higher $\mathrm{H}_{2} \mathrm{~S} / \mathrm{SO}_{2}$ average ratios than were found for the Rocknest soil sample -- 0.06 for John Klein (52) versus 0.01 for Rocknest (75). These data suggest a higher proportion of reduced sulfur relative to oxidized sulfur pointing to a plausible redox couple for prokaryotic respiration.

Iron also presents intriguing possibilities for redox coupling. CheMin analyses indicate the presence of a substantial quantity of likely authigenic magnetite ( $\sim 7 \%$ of crystalline components) in Sheepbed mudstones (28). The presence of an authigenic, partially reduced Fe-oxide phase in a Martian sedimentary rock represents a notable departure from previous secondary Fe-mineral detections on Mars, where ferric iron has proven to be the dominant redox state (76-78). The magnetite measured by CheMin does show evidence for oxidation of some of its ferrous iron to form the ferric defect-spinel maghemite (28). The gray color of the freshly exposed Sheepbed mudstone (Fig. 5f) contrasts sharply with the reddish color of the freshly exposed, highly oxidized, hematite-bearing rocks of Meridiani Planum (79) emphasizing the lower oxidation state of iron in the Sheepbed mudstone. There are a number of potential mechanisms for the production of authigenic magnetite, all of which are promoted by waters with relatively low Eh and neutral to alkaline $\mathrm{pH}(80)$. Under such conditions, aqueous $\mathrm{Fe}^{2+}$-hydroxide species can precipitate and ultimately transform to magnetite. Perhaps not coincidentally, neutral-to-alkaline $\mathrm{pH}$ conditions also are likely to promote the formation of clay minerals. Potential authigenic magnetite formation pathways include UV-promoted reactions with dissolved $\mathrm{Fe}^{2+}$ in the water column (81) or with carbonate minerals in the sediment (42), and partial oxidation of dissolved $\mathrm{Fe}^{2+}$ by dissolved $\mathrm{O}_{2}(80)$. Perhaps the most likely scenario is via clay formation and "saponitization" (28). However the magnetite may have formed, the additional presence of $\mathrm{Fe}^{3+}$ in nanophase iron oxide indicated by combined APXS/CheMin, and SAM data $(19,28,52)$, provides the other half of an iron-based redox couple in the Sheepbed mudstone.

Salinity provides another important constraint on habitability because it affects water activity, which, when low, can restrict cellular physiology (82-84). All natural waters contain dissolved ions that, through their interactions with water molecules, limit the availability of $\mathrm{H}_{2} \mathrm{O}$ for hydration reactions. Water activity is defined by microbiologists as $a_{\mathrm{w}}=\mathrm{n}_{1} /\left(\mathrm{n}_{1}+\mathrm{n}_{2}\right)$, where $\mathrm{n}_{1}$ equals moles of water and $\mathrm{n}_{2}$ equals moles of solute (82). Most terrestrial organisms cannot survive below $a_{\mathrm{w}}=0.9$, a few halophilic bacteria grow at $a_{\mathrm{w}}=0.85$, and some archaea can grow at $a_{\mathrm{w}}=0.75$ (83). In the Burns formation at Meridiani 
Planum, the abundance of calcium and magnesium sulfate minerals detected by the Opportunity rover is so great that it conservatively reconstructs to an ancient water activity of $a_{\mathrm{w}}=0.78-0.86$, and possibly as low as $a_{\mathrm{w}}=0.5(85)$. This shows that water activity was so low during deposition and diagenesis of the Burns formation that even though water was present, the environment would likely have been uninhabitable to all but the hardiest halophiles (86). In contrast, the Sheepbed mudstone provides evidence for both low salinity sediment-transporting water and early diagenetic water given its very low sulfur and chlorine content (19). It is possible that small amounts of chloride salt were present $(19,28)$, however, these were in low enough abundance $(<1-2 \%)$ so as to not substantially reduce water activity and create a challenge for prokaryotic microbes. Higher salinities are indicated for the waters that percolated through late diagenetic fractures; however, these were likely of modest salinity given their exclusively calcium sulfate composition (85). On Earth, calcium sulfate precipitation is common in evaporitic environments that thrive with diverse microorganisms (87). Furthermore, there is evidence that halophiles may resist the destructive effects of radiation (88), thought to limit habitability in the Martian surface environment (89).

Finally, estimates of pH are similarly important for understanding habitability. Again, in the Burns formation at Meridiani Planum, the presence of jarosite indicates low $\mathrm{pH}$ with ancient waters that contained sulfuric acid (40). However, such low pH does not discount the presence of life; terrestrial analog environments show that microbes can survive under these conditions because they have adapted their biochemistries to maintain near neutral conditions internally (90). Nevertheless, the presence of more neutral waters allows a broader range of microorganisms to be viable. The presence of clay minerals in the Sheepbed mudstone, absence of any evidence for Al mobility and the absence of iron sulfate minerals, even in the sulfate-filled late diagenetic veins, indicates a relatively neutral $\mathrm{pH}$. This neutral pH could have existed for all phases of aqueous history, from the primary waters of deposition that may have created a body of standing water, to early diagenesis, and through the close of late diagenesis.

At Yellowknife Bay there is no hint of the strongly acidic conditions that have been thought to especially describe the planet's younger history of aqueous alteration, sedimentation, and habitability $(74,83,91)$. The record of aqueous activity at Yellowknife Bay is likely prolonged and complex, involving several stages of diagenesis, including clay formation, that culminate with precipitation of calcium sulfate salts in veins, but without attendant indicators of acidic waters such as iron sulfates. The simplest interpretation of the sequence of diagenetic events would involve progressive desiccation of mildly saline, $\mathrm{pH}$ neutral waters - a very Earth-like scenario (92). Such conditions have been envisaged for the very early history of Mars (91), but it is only recently that they have been considered viable for a younger age $(7,93,94)$. The surprising result is that the stratigraphy of Yellowknife Bay may not only preserve evidence of a habitable environment, but one that is relatively young by Martian standards. In the most conservative scenario allowed by geologic mapping, the Yellowknife Bay formation represents part of the older fill of Gale crater, and therefore roughly Early Hesperian in age (6), perhaps overlapping with or postdating times of bedded sulfate formation elsewhere on Mars. This would indicate that times of sustained surface water, neutral $\mathrm{pH}$, and authigenic clay formation extended later 
into Mars' history. The potentially young age of clay formation (and habitability) does not invalidate the general trend that most rocks that interacted with water early in Mars' history produced clays, and those that interacted later produced sulfates. However, much like Earth's time-dependent records of iron formation $(95,96)$ and carbonates $(97,98)$, it points to the need to understand those special conditions which allow a distinctive aqueous environment to persist for broad spans of geologic time, or to recur when the favorable conditions again emerge. Curiosity's detection of a relatively young, and strikingly Earthlike habitable environment at Gale crater underscores the biologic potential of relatively young fluvio-lacustrine environments.

\section{References}

1. J. P. Grotzinger et al., Mars Science Laboratory Mission and Science Investigation. Space Science Reviews 170 (1-4), pp. 5-56 (2012).

2. R. P. I. Irwin, A. D. Howard, R. A. Craddock, J. M. Moore, An intense terminal epoch of widespread fluvial activity on early Mars: 2. Increased runoff and paleolake development. Journal of Geophysical Research 110, E12S14 (2005).

3. M. C. Malin, K. S. Edgett, Sedimentary Rocks of Early Mars. Science 290 (5498), pp. 1927-1937 (2000).

4. R. B. Anderson, J. F. B. III, Geologic mapping and characterization of Gale Crater and implications for its potential as a Mars Science Laboratory landing site. The Mars Journal 5, pp. 76-128 (2010).

5. R. E. Milliken, D. L. Bish, Sources and sinks of clay minerals on Mars. Philosophical Magazine 90 (1718), pp. 2293-2308 (2010).

6. B. J. Thomson et al., Constraints on the origin and evolution of the layered mound in Gale Crater, Mars using Mars Reconnaissance Orbiter data. Icarus 214 (2), pp. 413-432 (2011).

7. J. P. Grotzinger, R. E. Milliken, The sedimentary record of Mars: A golden decade of discovery. J. Grotzinger, R. E. Milliken, Eds., Mars Sedimentology (SEPM Special Publication, 2012), vol. 102.

8. J. P. Grotzinger, Beyond Water on Mars. Nature Geoscience 2 (4), pp. 231-233 (2009).

9. A. Fraeman et al., A hematite-bearing layer in Gale Crater: mapping and implications for past aqueous conditions. Geology, 41 (10) (2013).

10. This decision was made by the entire science team with strong consensus to drive a relatively short distance $(\sim 500 \mathrm{~m})$ to examine rocks with higher thermal inertia values that also had an apparently strong spatial association with the AF unit. The prediction based on mapping was that fluvial and/or lacustrine rocks potentially derived from the crater rim might be encountered. The strata exposed at the base of Mt. Sharp are still considered to be the primary mission objective and the team has established a departure date from Yellowknife Bay of the first week in July, 2013.

11. The names used for rock and soil targets studied by Curiosity and reported in this paper are derived from established rock formations of northern Canada. These names in turn derive from names of local geographic features where they occur, per convention, such as mountains, streams, lakes, bays, etc. This choice of naming scheme celebrates the city of Yellowknife, long known to be a port of departure for geologic mapping expeditions into some of the oldest rocks of North America. Yellowknife Crater was designated by the IAU, and Yellowknife Bay demarcates the area into which Curiosity descended to study its geologic history.

12. A base map was created based on $25 \mathrm{~cm} /$ pixel HiRISE visible image data, $1 \mathrm{~m} /$ pixel elevation data, and 100 $\mathrm{m} /$ pixel THEMIS thermal image data that was subdivided into $1401.2 \times 1.2 \mathrm{~km}(0.025$ degrees $)$ quadrangles and mapped in detail by over 30 team members. The group map was compiled, consolidated, and iteratively refined into a single GIS project.

13. In addition, minor units of eolian fill/bedforms and ejecta blankets adjacent to larger craters are present but are not discussed further.

14. Bradbury Landing refers to the patch of ground where Curiosity touched down on the surface of Mars. It commemorates the noted science fiction writer Raymond Bradbury, and was designated by NASA.

15. E. M. Stolper et al., The Petrochemistry of Jake_M: A Martian Mugearite. Science 341 (6153) (2013). 
16. P.-Y. Meslin et al., Soil diversity and hydration as observed by ChemCam at Gale crater, Mars. Science 341 (6153) (2013).

17. R. M. E. Williams et al., Martian Fluvial Conglomerates at Gale Crater. Science 340, 1068 (2013).

18. The morphology of the "bay" is the result of post-depositional erosion, perhaps by eolian processes, as shown by the exposures of stratified rock that record dissection; these are eroded rocks, and not, for example, shoreline berms. Therefore, the present-day topography does not reflect that at the time of deposition of those strata.

19. S. M. McLennan et al., Elemental Geochemistry of Sedimentary Rocks in Yellowknife Bay, Gale Crater, Mars. Science (2013 - submitted).

20. S. R. Taylor, S. M. McLennan, Planetary Crusts: Their Composition, Origin, and Evolution. (Cambridge University Press, Cambridge, 2009), pp. 378.

21. M. E. Schmidt et al., APXS of first rocks encountered by Curiosity in Gale Crater: Geochemical diversity and volatile element (K and Zn) enrichment. 44th Lunar and Planetary Science Conference, Abstract 1278. Houston, TX, (2013)

22. N. D. Smith, Some Sedimentological Aspects of Planar Cross-stratification in a Sandy Braided River. Journal of Sedimentary Petrology 42 (3), pp. 624-634 (1972).

23. G. A. Macdonald, Pahoehoe, Aa, and Block Lava. American Journal of Science 251, pp. 169-191 (1953).

24. A. Hurst, A. Scott, M. Vigorito, Physical characteristics of sand injectites. Earth Science Reviews 106 (34), pp. 215-246 (2011).

25. J. A. Ross, J. Peakall, G. M. Keevil, An integrated model of extrusive sand injectites in cohesionless sediments. Sedimentology 58 (7), pp. 1693-1715 (2011).

26. M. El-Tabak, R. Riccioni, B. C. Schreiber, Evolution of late Triassic rift basin evaporites (Passaic Formation): Newark Basin, Eastern North America. Sedimentology 44 (4), pp. 767-790 (2008).

27. J. A. Fisher, G. J. Nichols, D. A. Waltham, Unconfined flow deposits in distal sectors of fluvial distributary systems: Examples from the Miocene Luna and Huesca Systems, northern Spain. Sedimentary Geology 195 (1-2), pp. 55-73 (2007).

28. D. Vaniman et al., Mineralogy of a Mudstone on Mars. Science (2013 - submitted).

29. P. E. Potter, J. B. Maynard, P. Depetris, Mud and Mudstones. (Springer, 2005).

30. P. B. Attewell, I. W. Farmer, Principles of Engineering Geology. (Chapman and Hall, London and New York, 1976).

31. Supplementary materials are available on Science Online.

32. D. Winston, Fluvial Systems of the Precambrian Belt Supergroup, Montana and Idaho, U.S.A. Fluvial Sedimentology Memoir 5, 343 (1977).

33. D. S. McCormick, J. P. Grotzinger, Distinction of Marine from Alluvial Facies in the Paleoproterozoic (1.9 Ga) Burnside Formation, Kilohigok Basin, N.W.T., Canada. Journal of Sedimentary Petrology 63 (3), pp. 398-419 (1993).

34. A. S. Yen et al., An integrated view of the chemistry and mineralogy of martian soils. Nature 436 (7047), pp. 49-54 (2005).

35. P. R. Christensen, Regional dust deposits on Mars: Physical properties, age, and history. Journal of Geophysical Research: Solid Earth 91 (B3), pp. 2533-3545 (1986).

36. N. T. Bridges, D. R. Muhs, Duststones on Mars: source, transport, deposition, and erosion. Sedimentary Geology of Mars (SEPM Special Publication) 102, pp. 169-182 (2012).

37. N. Mangold, V. Ansan, P. Masson, C. Vincendon, Estimate of aeolian dust thickness in Arabia Terra, Mars: Implications of a thick mantle $(>20 \mathrm{~m})$ for hydrogen detection. Geomorphology: relief, processes, environment, pp. 23-32 (2009).

38. P. M. Sadler, Sediment accumulation rates and the completeness of stratigraphic sections. Journal of Geology 89 (5) (1981).

39. A. M. Sarna-Wojcicki, S. Shipley, R. B. Waitt, D. Dzurisin, S. H. Wood, in The 1980 eruptions of Mount St. Helens, Washington, P. W. Lipman, D. R. Mullineaux, Eds. (U.S. Geological Survey Professional Paper, 1981), vol. 1250, pp. 577-600.

40. S. M. McLennan et al., Provenance and diagenesis of the evaporite-bearing Burns formation, Meridiani Planum, Mars. Earth and Planetary Science Letters 240, 95 (2005).

41. P. Fralick, J. P. Grotzinger, L. Edgar, in Sedimentary geology of Mars, J. P. Grotzinger, R. E. Milliken, Eds. (SEPM Special Publication, 2012), vol. 102. 
42. J. D. Kim, N. Yee, V. Nanda, P. G. Falkowski, Anoxic photochemical oxidation of siderite generates molecular hydrogen and iron oxides. Proceedings of the National Academy of Sciences of the United States of America 110 (25), pp.10073-10077 (2013).

43. G. Furniss, J. F. Rittel, D. Winston, Gas bubble and expansion crack origin of "molar-tooth" calcite structures in the Middle Porterozoic Belt Supergroup, Western Montana. Journal of Sedimentary Research 68, pp.104-114 (1998).

44. The term "raised ridges" may seem redundant, but the designation "raised" is meant to denote the significant height of the ridges compared to their width.

45. P. S. Plummer, V. A. Gostin, Shrinkage Cracks: Desiccation or Synaeresis? Journal of Sedimentary Research 51, pp. 1147-1156 (1981).

46. B. R. Pratt, Syneresis cracks: subaqueous shrinkage in argillaceous sediments caused by earthquakeinduced dewatering. Sedimentary Geology 117, 1 (1998).

47. M. D. Pollack, L. C. Kah, J. K. Bartley, Morphology of Molar-Tooth Structures in Precambrian Carbonates: Influence of Substrate Rheology and Implications for Genesis. Journal of Sedimentary Research 76, 310 (2006).

48. A. Hurst, J. A. Cartwright, D. Duranti, in Subsurface Sediment Mobilisation, R. R. H. P. Van Rensbergen, A.J. Maltman, C.K. Morley, Ed. (Geological Society of London Special Publication, 2003), vol. 216, pp. 123-137.

49. I. A. Kane, Development and flow structures of sand injectities: The Hind Sandstone Member injectite complex, Carboniferous, UK. Marine and Petroleum Geology 27 (6), pp. 1200-1215 (2010).

50. M. Huuse, J. Cartwright, A. Hurst, N. Steinsland, Seismic Characterization of Large-scale Sandstone Intrusions. A. H. a. J. Cartwright, Ed., Sand injectities: Implications for hydrocarbon exploration and production (AAPG Memoir, 2007), vol. 87.

51. J. W. Cosgrove, Hydraulic fracturing during the formation and deformation of a basin: A factor in the dewatering of low-permeability sediments. AAPG Bulletin 85 (4), pp. 737-748 (2001).

52. D. W. Ming et al., Organic, Volatile, and Isotopic Compositions of a Sedimentary Rock in Yellowknife Bay, Gale crater, Mars. Science (2013 - submitted).

53. J. D. Collinson, Sedimentology of unconformities within a fluvio-lacustrine sequence; Middle Proterozoic of Eastern North Greenland. Sedimentary Geology 34 (2-3), pp. 145-166 (1983).

54. L. B. Aspler, J. R. Chiarenzelli, B. L. Cousens, Fluvial, lacustrine and volcanic sedimentation in the Angikuni sub-basin, and initiation of $\sim 1.84-1.79$ Ga Baker Lake Basin, western Churchill Province, Nunavut, Canada. Precambrian Research 129 (3-4), pp. 225-250 (2004).

55. H. H. Kieffer, B. M. Jakosky, C. Snyder, M. Matthews, Mars. H. H. Kieffer, B. M. Jakosky, C. Snyder, M. Matthews, Eds., (University of Arizona Press, Tucson, 1992).

56. J. F. Bell III, The Martian Surface: Composition, Mineralogy, and Physical Properties. J. Bell, Ed., (Cambridge University Press, New York, 2008).

57. J. C. Andrews-Hanna, K. W. Lewis, Early Mars hydrology: 2. Hydrological evolution in the Noachian and Hesperian epochs. Journal of Geophysical Research: Planets 116 (E2), (2011).

58. C. R. Woese, G. E. Fox, Phylogenetic structure of the prokaryotic domain: The primary kingdoms. Proc. Natl. Acad. Sci. USA 74 (11), pp. 5088-5090 (1977).

59. I. E. Friedmann, Endolithic microorganisms in the Antarctic cold desert. Science 215, pp. 1045-1053 (1982).

60. K. O. Stetter, Extremophiles and their adaptation to hot environments. FEBS letters 452.1, pp. 22-25 (1999).

61. M. Rossi et al., Extremophiles 2002. Journal of bacteriology 185 (13) pp. 3683-3689 (2003).

62. K. H. Nealson, Sediment bacteria: who's there, what are they doing and what's new? A. Rev. Earth Planet. Sci. 25, pp. 403-434 (1977).

63. H. G. Schlegel, General Microbiology. (Cambridge University Press, ed. 7th Edition, 1993).

64. G. Gottschalk, Microbial metabolism. (Springer, New York, 1994).

65. R. J. Parkes et al., Deep sub-seafloor prokaryotes simulated at interfaces over geologic time. Nature 436, pp. 390-394 (2005).

66. K. H. Nealson, P. G. Conrad, Life: past, present and future. Phil. Trans. R. Soc. Lond. B. Millenium Issue, 1923 (1999).

67. D. Z. Sousa et al., Activity and viability of methanogens in anaerobic digestion of unsaturated and saturated long-chain fatty acids. Applied and Environmental Microbiology 79 (14) (2013). 
68. M. S. Milman-Barris et al., Zoning of phosphorous in igneous olivine. Contributions to Mineralogy and Petrology 155 (6), pp. 739-765 (2008).

69. M. A. Schoonen, Y. Xu, Nitrogen Reduction Under Hydrothermal Vent Conditions: Implications for the Prebiotic Synthesis of C-H-O-N Compounds. Astrobiology 11 (2), pp. 133-142 (2001).

70. D. P. Summers, R. C. B. Basa, B. Khare, D. Rodoni, Abiotic Nitrogen Fixation on Terrestrial Planets: Reduction of NO to Ammonia by FeS. Astrobiology 12 (2), pp. 107-114 (2012).

71. V. I. Oyama, B. J. Berdahl, G. C. Carle, Preliminary findings of the Viking gas exchange experiment and a model for Martian surface chemistry. Nature 265, pp. 110-114 (1977).

72. H. P. Klein, The Viking Biological Investigation: General aspects. Journal of Geophysical Research 82 (28), pp. 4677-4680 (1977).

73. M. H. Hecht et al., Detection of Perchlorate and the Soluble Chemistry of Martian Soil at the Phoenix Lander Site. Science 325 (5936), pp. 64-67 (2009).

74. S. W. Squyres, A. H. Knoll, Sedimentary rocks and Meridiani Planum: Origin, diagenesis, and implications for life of Mars. Earth and Planetary Science Letters 240 (1), pp. 1-10 (2005).

75. L. A. Leshin et al., Volatile, Isotope and Organic Analysis of Solid Samples with the Mars Curiosity Rover. Science 341 (6153) (2013).

76. R. E. Milliken et al., Opaline silica in young deposits on Mars. Geology 36 (11), pp. 847-850 (2008).

77. R. V. Morris et al., Mössbauer mineralogy of rock, soil, and dust at Gusev crater, Mars: Spirit's journey through weakly altered olivine basalt on the plains and pervasively altered basalt in the Columbia Hills. Journal of Geophysical Research - Planets 111 (E2), pp. 1991-2012 (2006).

78. R. V. Morris et al., Mossbauer mineralogy of rock, soil, and dust at Meridiani Planum, Mars: Opportunity's journey across sulfate-rich outcrop, basaltic sand and dust, and hematite lag deposits. Journal of Geophysical Research 111 (E12S15) (2006).

79. J. F. Bell et al., Pancam Multispectral Imaging Results from the Opportunity Rover at Meridiani Planum. Science 306 (5702), pp. 1703-1709 (2004).

80. R. M. Cornell, U. Schwertmann, The Iron Oxides: Structure, Properties, Reactions, Occurrence and Uses. W. Wiley-VCH Verlag GmbH \& Co, Ed., 2nd edition (2003), pp. 664.

81. G. N. Schrauzer, T. D. Guth, Hydrogen evolving systems. 1. The formation of molecular hydrogen from aqueous suspensions of iron(II) hydroxide and reactions with reducible substrates, including molecular nitrogen. Journal of the American Chemical Society 98 (12), pp. 3508-3513 (1976).

82. W. D. Grant, Life at low water activity. Philosophical Transactions of the Royal Society of London. Series B: Biological Sciences 359 (1448), pp. 1249-1267 (2004).

83. A. H. Knoll, J. Grotzinger, Water on Mars and the Prospect of Martian Life. Elements 2 (3), pp. 169-173 (2006).

84. J. P. Williams, J. E. Hallsworth, Limits of life in hostile environments: no barriers to biosphere function? Environmental Microbiology 11 (12), pp. 3292-3308 (2009).

85. N. J. Tosca, A. H. Knoll, S. M. McLennan, Water Activity and the Challenge for Life on Early Mars. Science 320 (5880), pp. 1204-1207 (2008).

86. S. Fendrihan et al., Spherical particles of halophilic archaea corelate wtih exposure to low water activity implications for microbial survival in fluid inclusions of ancient halite. Geobiology 10 (5), pp. 424-433 (2012).

87. C. Demergasso et al., Distribution of prokaryotic genetic diversity in athalassohaline lakes of the Atacama Desert, Northern Chile. FEMS Microbiology Ecology 48 (1), pp. 57-69 (2004).

88. A. Kish et al., Salt shield: intracellular salts provide cellular protection against ionizing radiation in the halophilic archaeon, Halobacterium salinarum NRC-1. Environmental Microbiology 11 (5), pp. 1066-1078 (2009).

89. L. R. Dartnell, L. Desorgher, J. M. Ward, A. J. Coates, Modelling the surface and subsurface Martian radiation environment: Implications for astrobiology. Geophysical Research Letters 34 (2), L02207 (2007).

90. A. I. Lopez-Archilla, I. Marin, R. Amils, Microbial Community Composition and Ecology of an Acidic Aquatic Environment: The Tinto River, Spain. Microbial Ecology 41 (1), pp. 20-35 (2001).

91. J.-P. Bibring et al., Global Mineralogical and Aqueous Mars History Derived from OMEGA/Mars Express Data. Science 312 (5772), pp. 400-404 (2006).

92. T. F. Bristow, R. E. Milliken, Terrestrial perspective on authigenic clay mineral production in ancient Martian lakes. Clays and Clay Minerals 59 (4), pp. 339-358 (2011).

93. S. L. Murchie et al., A synthesis of Martian aqueous mineralogy after 1 Mars year of observations from the Mars Reconnaissance Orbiter. Journal of Geophysical Research: Planets 114 (E2), E00D06 (2009). 
94. A. G. Fairen et al., Noachian and more recent phyllosilicates in impact craters on Mars. Proceedings of the National Academy of Sciences of the United States of America 107 (27), pp. 12095-12100 (2010).

95. H. L. James, A. F. Trendall, Banded Iron Formation: Distribution in time and Paleoenvironmental Significance. H. D. H. a. M. Schidlowski, Ed., Mineral Deposits and the Evolution of the Biosphere: Dahlem Workshop Report (Springer-Verlag, Berlin, Heidelberg, New York, 1982), vol. 3.

96. A. Bekker et al., Iron Formation: The Sedimentary Product of a Complex Interplay among Mantle, Tectonic, Oceanic, and Biospheric Processes. Economic Geology 105 (3), pp. 467-508 (2010).

97. J. P. Grotzinger, in Controls on Carbonate Platforms and Basin Development, P. D. Crevello, J. L. Wilson, J. F. Sarg, J. F. Read, Eds. (SEPM Special Publication, 1989), vol. 44, pp. 79-106.

98. J. P. Grotzinger, N. P. James, in Carbonate Sedimentation and Diagenesis in the Evolving Precambrian World, J. P. Grotzinger, N. P. James, Eds. (SEPM Special Publication, 2000), vol. 67, pp. 3-20.

99. K. W. Lewis et al., Quasi-Periodic Bedding in the Sedimentary Rock Record of Mars. Science 322 (5907), pp. 1532-1535 (2008).

100. R. C. Anderson et al., Collecting Samples in Gale Crater, Mars; an Overview of the Mars Science Laboratory Sample Acquisition, Sample Processing and Handling System. Space Science Reviews 170 (14), pp. 57-75 (2012).

\section{Acknowledgements}

The authors are indebted to the Mars Science Laboratory Project engineering and management teams, for their exceptionally skilled and diligent efforts in making the mission as effective as possible and enhancing science operations. We are also grateful to all those MSL team members who participated in tactical and strategic operations. Without the support of both the engineering and science teams, the data presented here could not have been collected. Some of this research was carried out at the Jet Propulsion Laboratory, California Institute of Technology, under a contract with the National Aeronautics and Space Administration. Data presented in this paper are archived in the Planetary Data System (pds.nasa.gov) 


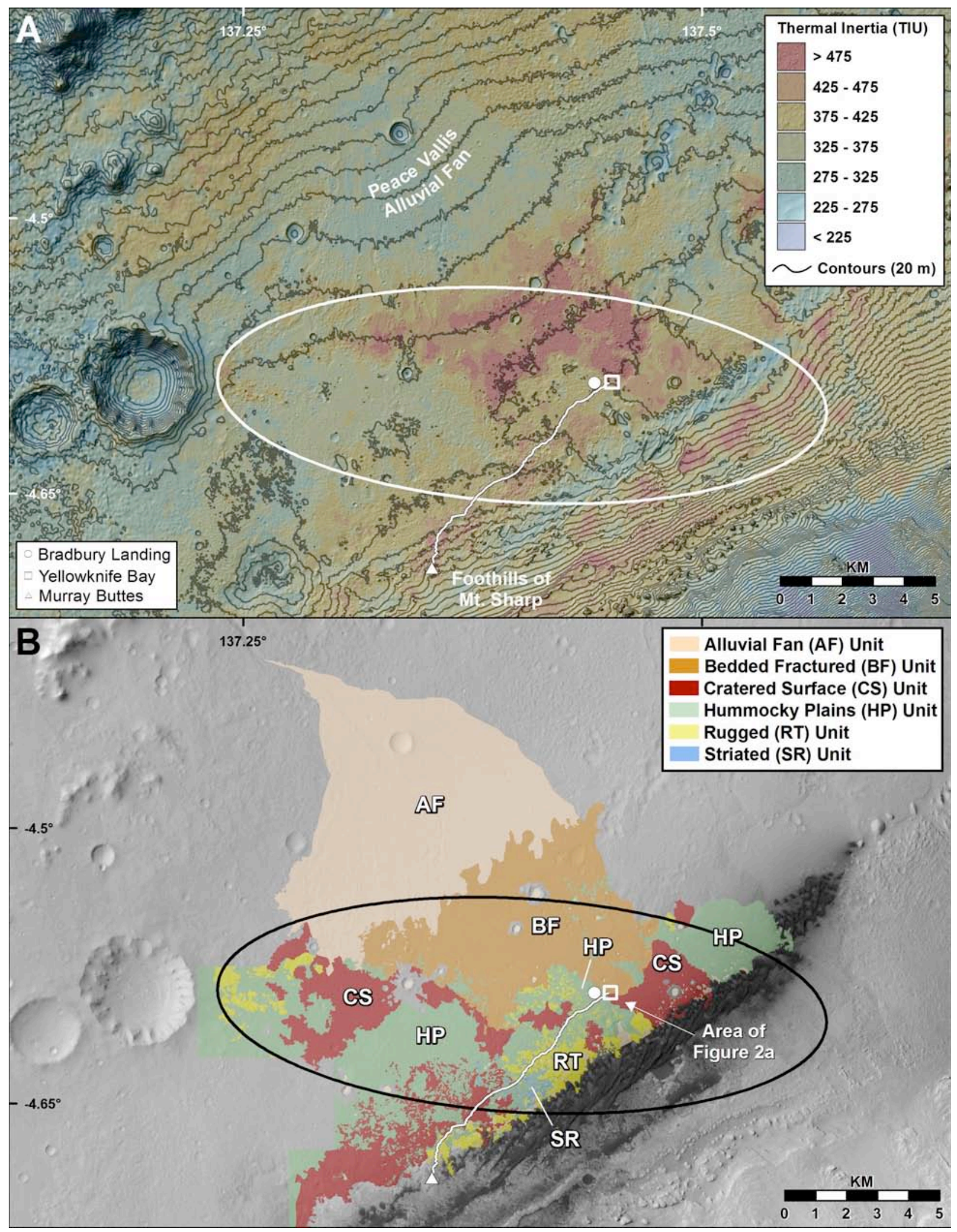


Fig. 1: Regional context maps. (A) Location of Bradbury landing site and Yellowknife Bay in relationship to the topography and thermal inertia of the broad valley between Gale's crater rim and Mt. Sharp. White ellipse is the landing ellipse. White line represents intended drive route from Yellowknife Bay to Mt. Sharp entry point at Murray Buttes. (B) A geological map was constructed based largely on HiRISE image data and used to demarcate major terrain types for exploration by Curiosity. The MSL science team chose to drive the rover to Yellowknife Bay where three terrains intersect in a triple junction. One of these terrains (BF) very closely coincides with higher values of thermal inertia, and it was also recognized that rocks at Yellowknife Bay are downslope of those forming the AF unit, suggesting a genetic link. The legend for symbols in Fig. 1A applies to Fig. 1B. Black ellipse is the landing ellipse. White line represents intended drive route from Yellowknife Bay to Mt. Sharp entry point.

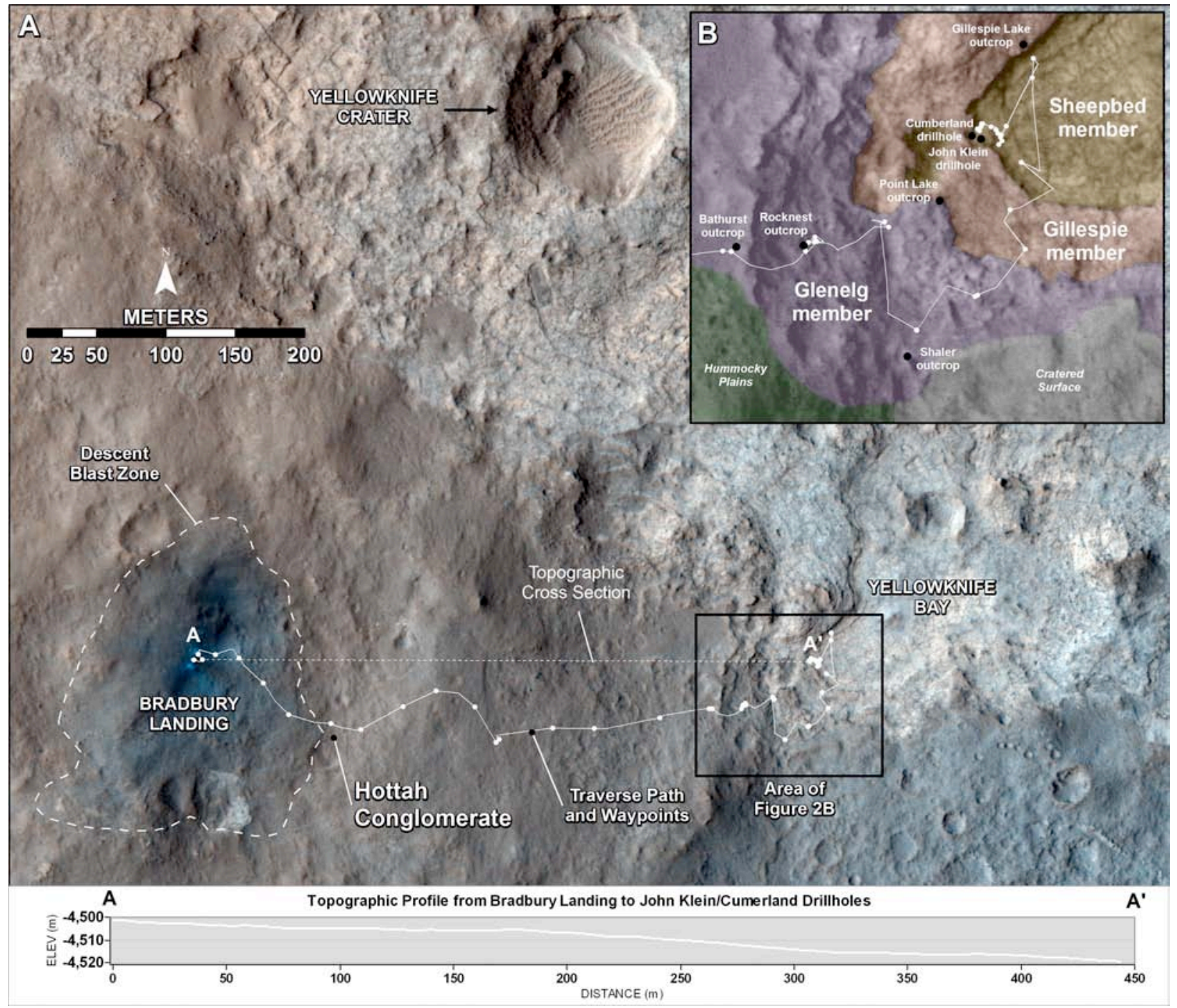

Fig. 2. Local context maps. (A) HiRISE image (PSP_010573_1755)of Bradbury Landing showing Curiosity's position after landing and path of eventual traverse to Yellowknife Bay, 
where the John Klein and Cumberland holes were drilled. Area of image is approximated by circle and square symbols in Fig. 1b. Yellowknife Bay derives its name from Yellowknife crater, which is located within the broad expanse of the BF map unit. The BF unit likely represents the Yellowknife Bay formation at more regional scales. Cross-section A-A' shows topography from Bradbury Landing to Yellowknife Bay. (B) Inset shows detailed geological map of southwest part of Yellowknife Bay. Three maps units (HP, CS, BF) intersect just south of the Shaler outcrop. The BF map unit is subdivided into three members (see text). Key outcrops are shown that provided information leading to the development of a stratigraphy shown in Fig. 4. Note that the contact between Sheepbed member and Gillespie Lake member erodes to form a topographic step that is visible from orbit and can be traced for hundreds of meters around Yellowknife Bay. Therefore, it seems likely that much of the Yellowknife "Bay" topographic depression was created by eolian erosion of the Sheepbed mudstone member (see text). See Fig. 4 for mapped stratigraphic units. Locations of Rocknest (scoop location, and rocky outcrops), and John Klein and Cumberland (drill) sampling locations are shown.

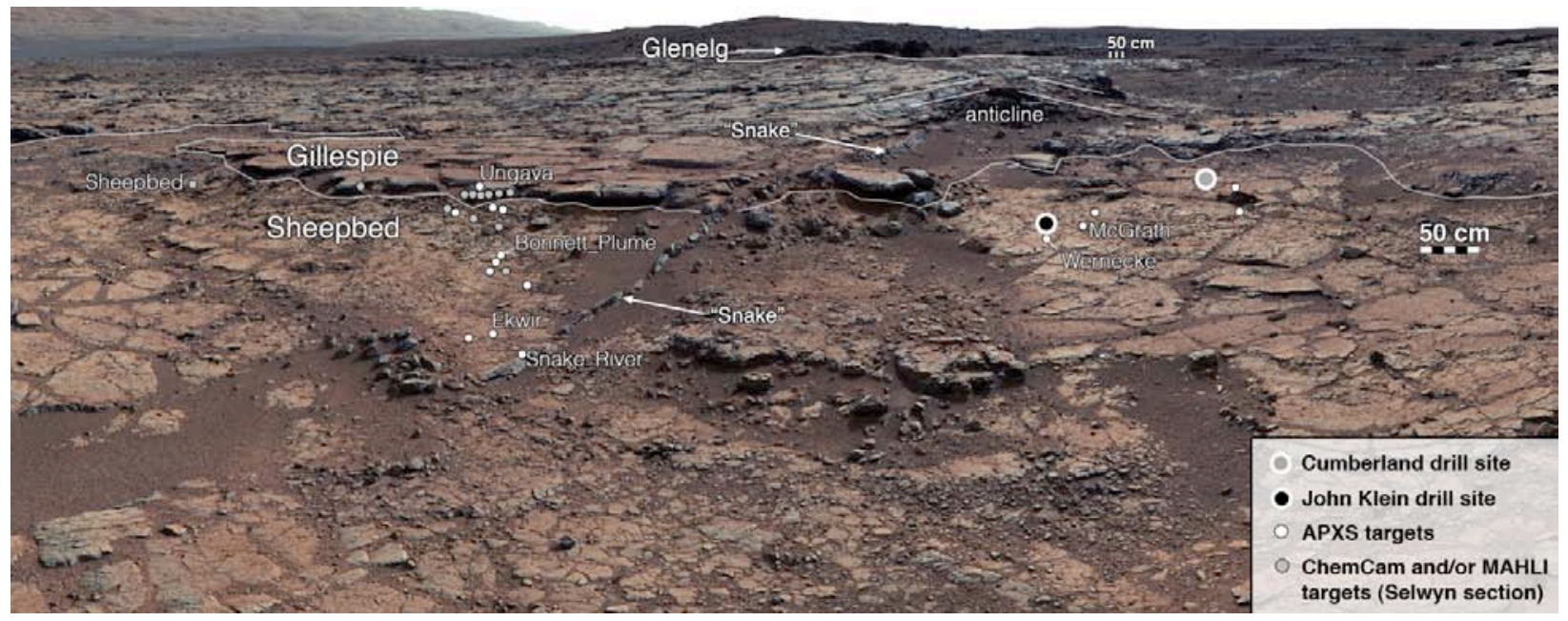

Fig. 3. Mastcam mosaic of Yellowknife Bay formation. View from base of exposed section up through Sheepbed, Gillespie Lake, and basal Glenelg members. Location of drill holes and APXS measurements is shown. High density of APXS measurements between Snake River and Ungava targets delineates the route of the Selwyn reference section. Note the "snake" feature cutting up through the section and terminating in small anticline. White dots represent combined APXS, MAHLI, and ChemCam measurements; Gray dots, ChemCam or MAHLI only. Both scale bars are $50 \mathrm{~cm}$ long with $10 \mathrm{~cm}$ spaced white and black sections. The lower scale bar is about 8 meters away from Curiosity, the upper scale bar is about $30 \mathrm{~m}$ away. The 111-image mosaic was acquired on Sol 137, by M-34 sequence 818. This figure shows only a small portion of the full mosaic. The foothills of Mt. Sharp are visible in the distance, upper left, southwest of camera position. For mosaic image IDs see (31). 


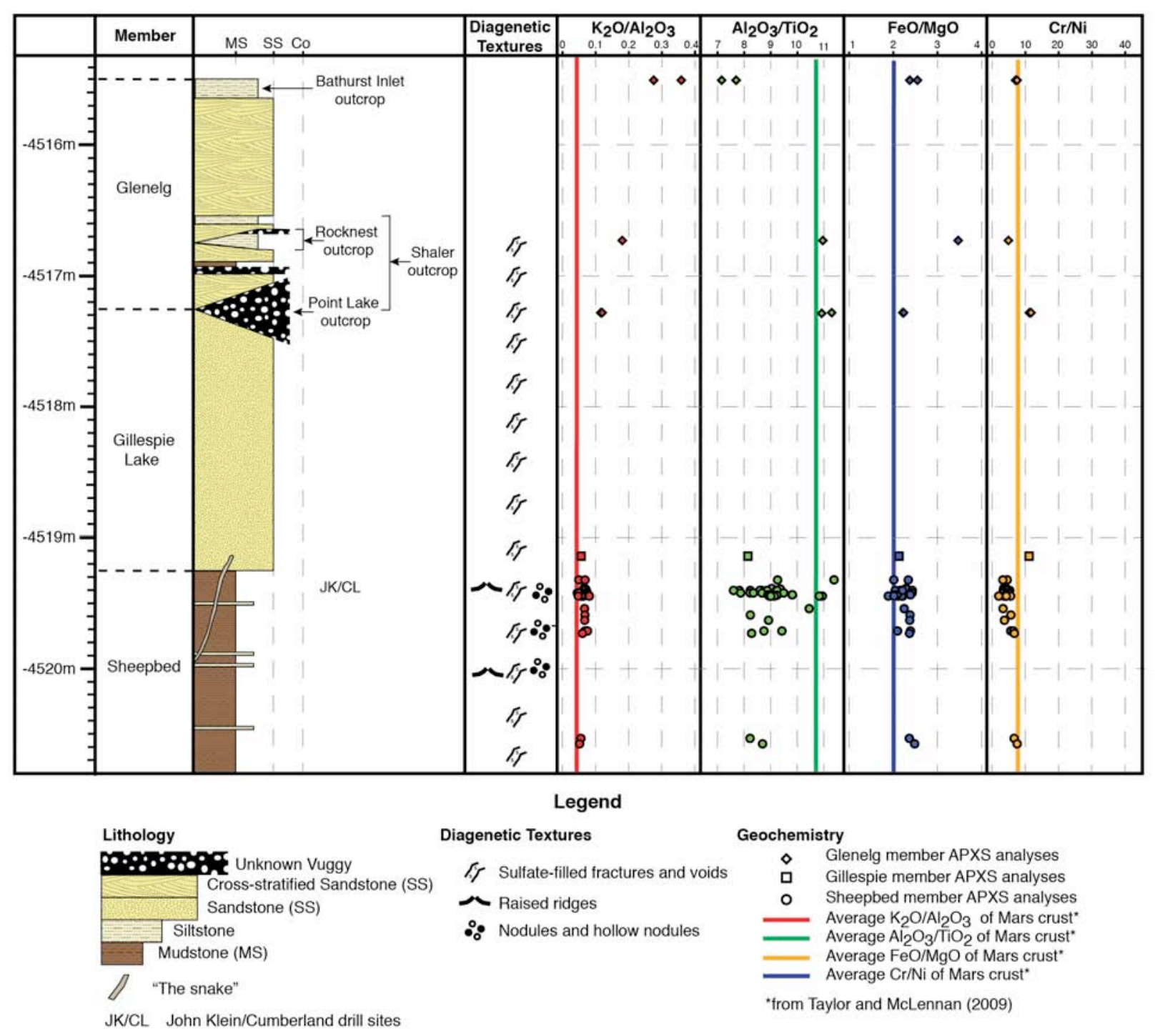

Fig. 4. Stratigraphy of the Yellowknife Bay formation plotted with elemental and oxide ratios measured by the Curiosity APXS instrument. The Yellowknife Bay section was split into three members distinguished by lithological properties (facies, textures), chemical composition, and attributes observed from orbit by HiRISE. The stratigraphic column highlights differences in grain size between the Yellowknife Bay members and the presence of stratification styles, primary textures, and diagenetic textures including nodules, hollow nodules, raised ridges, sulfate-filled fractures, and vugs. APXS analyses are plotted as ratios to highlight compositional trends throughout the Yellowknife Bay formation. Average Mars crustal composition for each ratio (colored vertical lines) (20) is plotted for comparison to Curiosity APXS measurements. 


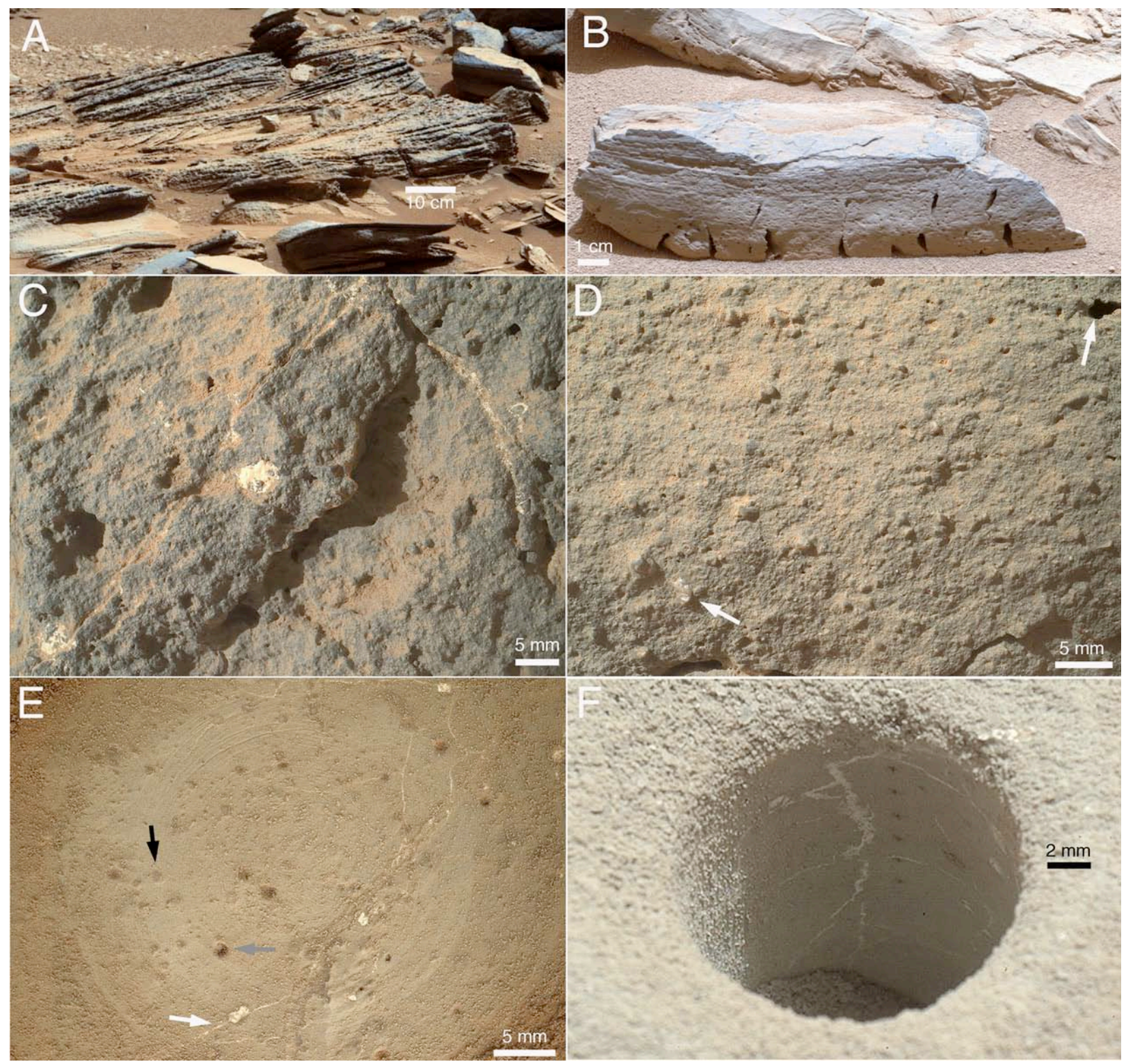

Fig. 5. Sedimentary rocks of the Yellowknife Bay formation. (A) Shaler outcrop shows a variety of facies including compound cross-bedding. The image was white balanced and acquired by Mastcam-100 on sol 120. Image ID is 0120MR0007520130200690E01_DXXX. (B) Rocknest-3 rock, which represents the middle part of the Glenelg member, is finegrained with planar lamination, shrinkage cracks, and mm-scale voids (well-developed in lower third of rock). Subset of a mosaic of images that were white-balanced and acquired with Mastcam--100 on sol 59. Image IDs, as part of SEQID mcam00270 are 0059MR0002700000103141E01_DXXX, 0059MR0002700010103142E01_DXXX, 0059MR0002700020103143E02_DXXX, 0059MR0002700030103144E01_DXXX. (C) Vuggy, medium-grained texture in Point Lake outcrop ("Measles Point" target), middle of Point Lake member. Note thin fractures filled with light toned material, interpreted as sulfate. ChemCam data show that white blebs, such as the one in the center, are composed of calcium sulfate. This focus merge product was acquired by MAHLI on sol 303, 
ID 0303MH0002900000103786R00. (D) Medium to coarse-grained sandstone at the Gillespie Lake outcrop (see Fig. 2b), basal bed of Gillespie Lake member. This bed is composed of poorly sorted, moderately well rounded, dark to light grains, some of which have glassy luster (lower left arrow). A small amount of vuggy porosity is evident (upper right arrow) but otherwise the rock appears well cemented. The image was acquired by MAHLI on sol 132, ID 0132MH0001580010101221E01. (E) Mudstone in Sheepbed member, "Wernecke target" (see Fig. 3). Rock has been brushed revealing homogeneous, fine-grained texture. Outlines of nodules (black arrow), void spaces (gray arrow), and sulfate-filled voids can be seen and only those voids connected by hairline fractures (white arrow) have been filled with sulfates. Note scoring of surface by brush bristles indicating softness of mudstone. The image was acquired by MAHLI on sol 169,

ID 0169MH0002080020102218C00. (F) John Klein drill hole (see Fig. 3) reveals gray colored cuttings, rock powder and interior wall. Note homogeneous, fine grain size of mudstone, and irregular network of sulfate-filled hairline fractures. Array of eight ChamCam shot points can be seen. Diameter of hole is $1.6 \mathrm{~cm}$. The image was acquired by MAHLI on sol 270, ID 0270MH0002540050102794C00.

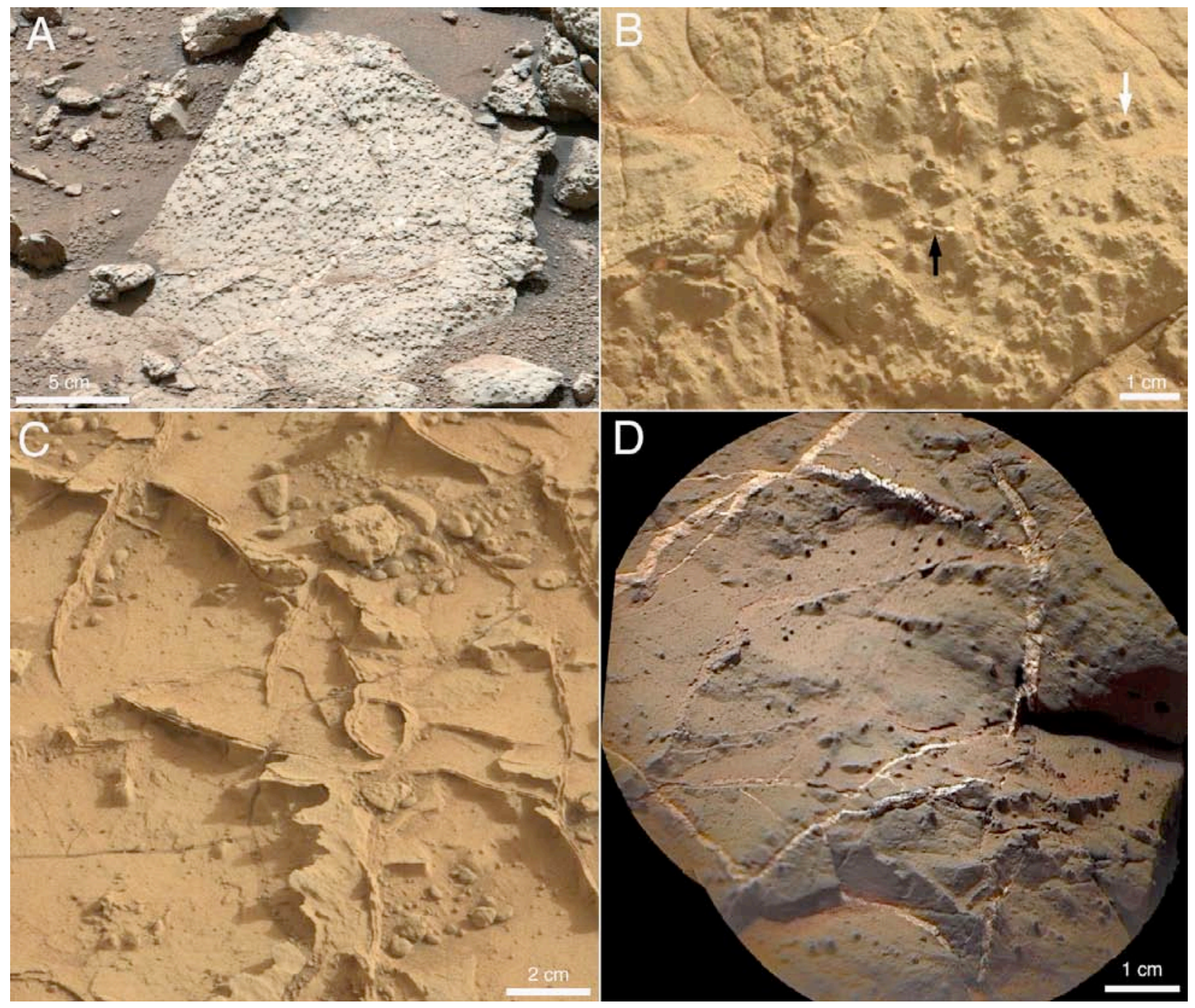


Fig. 6. Diagenetic features of the Sheepbed member. (A) Sheepbed target shows that millimeter-scale nodules, interpreted as concretions, are locally abundant. Note their dispersed distribution. Outcrop is crosscut by sulfate-filled fractures. Subset of a mosaic acquired by Mastcam-34 on sol 192. Image IDs are 0192ML0010170240105705E01_DXXX, and 0192ML0010170070105688E01_DXXX. The image has been white balanced. (B) Hollow nodules at the "Bonnett Plume" target (see Fig. 3) are defined by circular crosssections through voids with raised rims (white arrow). Voids are filled with sulfate minerals where intersected by hairline fractures (black arrow) but are otherwise unfilled. The image was white balanced and acquired by Mastcam-100 on sol 159. Image ID is 0159MR0008640050201360E01_DXXX. (C) Raised ridges near the McGrath target have spindle-shaped terminations (see Fig. 3). Note broadly varying strikes and with dips ranging from vertical to 45 degrees. Ridges most commonly have parallel sides, but also have one or two additional infilling bands. All contour the local topography of the fracture margin and are interpreted as infilling cements. The image was white balanced and acquired by Mastcam-100 on sol 164. Image ID is 0164MR0008850000201589E01_DXXX. (D) Sulfate-filled fractures at Sheepbed target (see Fig. 3) are consistent with brittle deformation of lithified mudstone, followed by precipitation of sulfate from mineralizing fluids. Also note abundant mm-scale nodules. The fracture fills mostly are flush with the bedrock surface, which contrasts with the nodules that weather in relief. Image is a ChemCam RMI mosaic that has been pan-sharpened using Mastcam-100 color data that has been white balanced. Images used in this composite are:

CR0_408676341EDR_F0051398CCAM01126M1, CR0_408675268EDR_F0051398CCAM01126M1, and Mastcam-100 ID 0126MR0007800000200786E01_DXXX. 

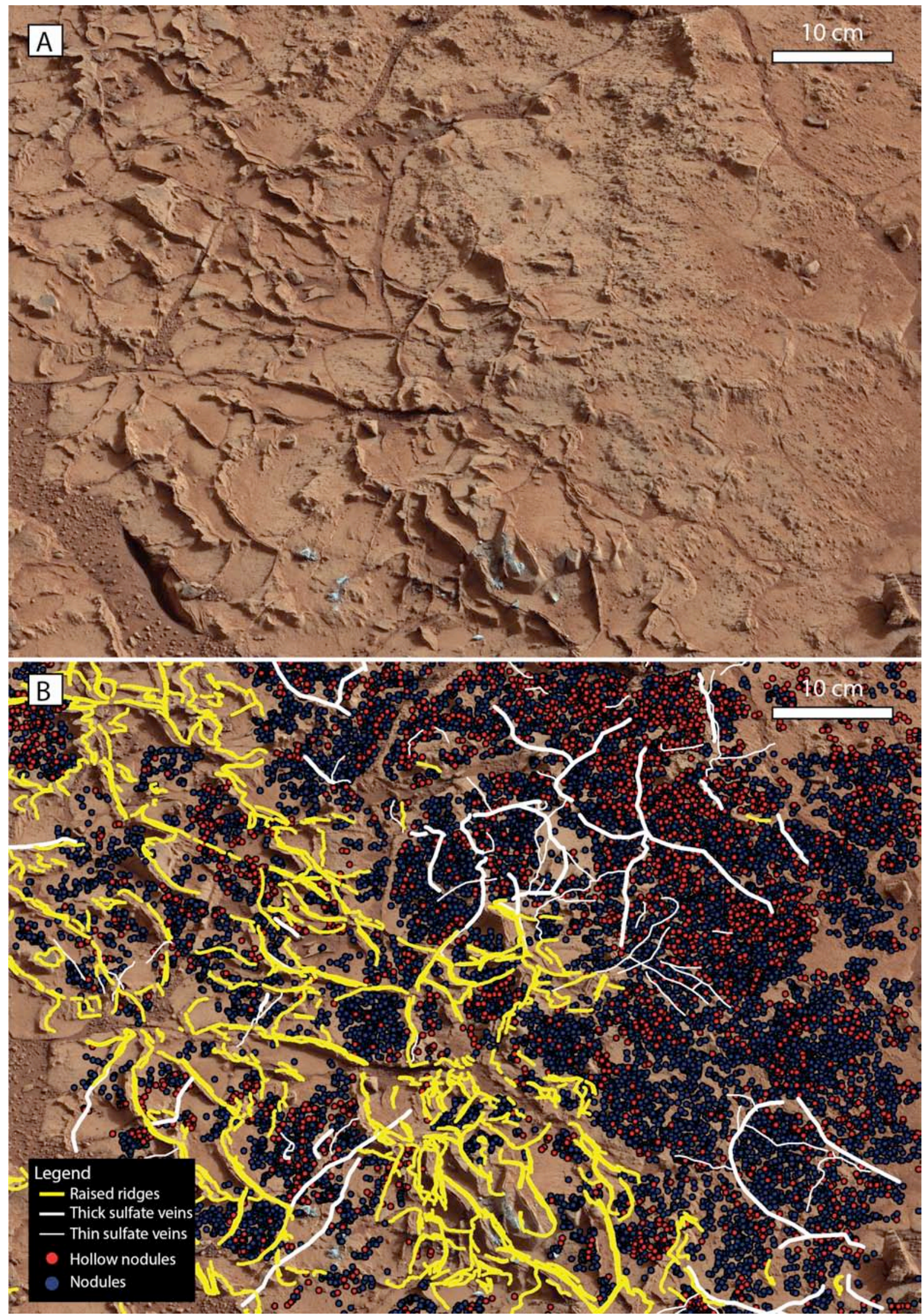
Fig. 7. Map of diagenetic features showing spatial relationships between fabric elements. The rock surface coincides with a bedding plane. Note that nodules and hollow nodules pass laterally into raised ridges suggesting variations in lithologic or diagenetic fluid properties (see text). (A) Subset of the Mastcam-100 workspace mosaic acquired by the Curiosity on Sol 164. This perspective mosaic is white-balanced and was used as a base map. (B) The Sol 164 workspace mosaic annotated to show the distribution of early diagenetic features (nodules, hollow nodules, raised ridges) and later diagenetic features (thick to thin sulfate-filled fractures). Erosion-resistant raised ridges were outlined individually and generally exhibit parallel sets of isopachous linings. Thin ( $<5 \mathrm{~mm}$ in width) sulfate veins have relatively constant thickness whereas thicker sulfate veins have more variable thickness. Both sets of veins crosscut other diagenetic features. Hollow nodules are circular features ( $\sim 1 \mathrm{~mm}$ in diameter) that stand out in raised relief from the outcrop surface and are distinguished from nodules by the presence of a small depression in the center of the feature. Because hollow nodule diameters often are at or below the resolution limits of this mosaic (confirmed by MAHLI observations), hollow nodules are likely underrepresented relative to nodules. Subset of the Mastcam-100 workspace mosaic from sol 164. For mosaic image IDs see (31). 


\title{
Supplementary Material
}

\author{
Table S1. Stratigraphic Nomenclature
}

\begin{tabular}{|c|c|c|}
\hline Name & Unit Description & Exposure and Contacts \\
\hline $\begin{array}{l}\text { Glenelg } \\
\text { member }\end{array}$ & 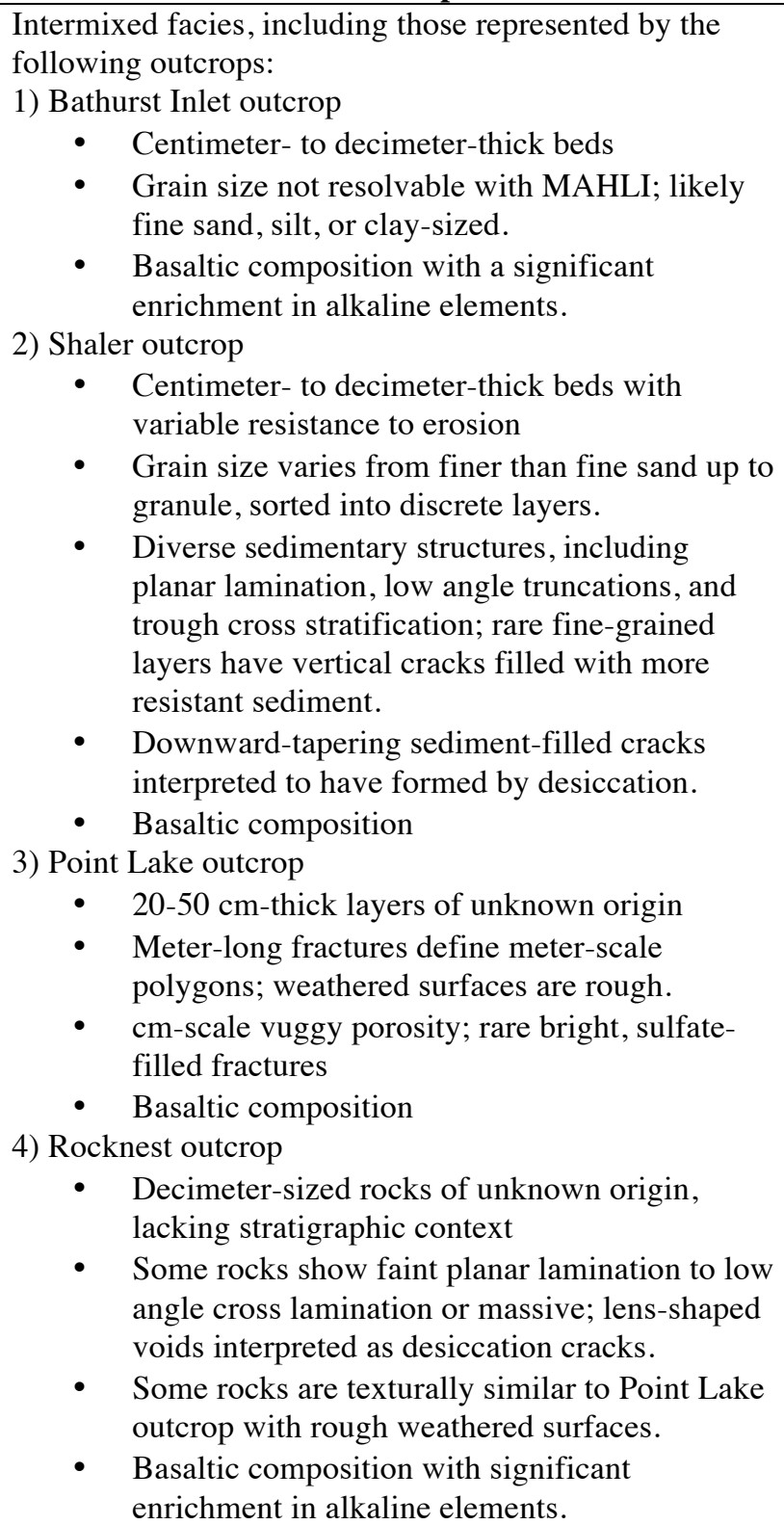 & $\begin{array}{l}\text { - Caps Yellowknife Bay formation } \\
\text { stratigraphy. The "cratered surface" } \\
\text { map unit, to the southeast of } \\
\text { Yellowknife Bay, may represent the } \\
\text { expression of the upper surface of a } \\
\text { resistant bed near the top of the } \\
\text { formation, or the top of the formation } \\
\text { itself. } \\
\text { - } \quad \text { Upper beds (e.g. Bathurst Inlet } \\
\text { outcrop) weather resistantly, and } \\
\text { typically overlie slopes covered with } \\
\text { scree, which may be underlain by facies } \\
\text { similar to those in the Shaler outcrop. } \\
\text { - Facies represented by the Point } \\
\text { Lake and Rocknest outcrops are } \\
\text { exposed as discontinuous layers and a } \\
\leq 200 \text { m }{ }^{2} \text { platform of resistant beds. } \\
\text { - Lower contact: sharp with the } \\
\text { underlying Gillespie Lake member. } \\
\text { - Upper contact: not exposed, or } \\
\text { consists of the geomorphic cratered } \\
\text { surface. }\end{array}$ \\
\hline $\begin{array}{l}\text { Gillespie } \\
\text { Lake } \\
\text { member }\end{array}$ & $\begin{array}{l}\text { - Decimeter-thick beds of uniformly smooth } \\
\text { weathering sandstone; } \\
\text { - } \quad \text { Meter-long fractures define meter-scale } \\
\text { polygons; } \\
\text { - } \quad \text { Medium to very coarse sand with diverse grain }\end{array}$ & $\begin{array}{l}\text { - Well exposed and laterally } \\
\text { continuous regionally. } \\
\text { - Lower contact: sharp with } \\
\text { centimeters of relief; lowermost bed } \\
\text { always caps a small scarp, often }\end{array}$ \\
\hline
\end{tabular}




\begin{tabular}{|c|c|c|}
\hline & $\begin{array}{l}\text { colors and some translucent grains at base of the unit } \\
\text { - Hints of small-scale cross stratification } \\
\text { including possible ripple crests on bedding planes. } \\
\text { - } \quad \text { Rare millimeter-scale bright, sulfate-filled } \\
\text { fractures. } \\
\text { - } \quad \text { Basaltic composition }\end{array}$ & $\begin{array}{l}\text { overhanging. Contact is nearly } \\
\text { horizontal for } 100 \text { 's } \mathrm{m} \text { to the east and } \\
\text { northeast. } \\
\text { - Upper contact: sharp and well } \\
\text { exposed under the Point Lake outcrop, } \\
\text { but poorly exposed elsewhere. }\end{array}$ \\
\hline $\begin{array}{l}\text { Sheepbed } \\
\text { member }\end{array}$ & $\begin{array}{l}\text { - Decimeter-thick beds with variable resistance to } \\
\text { erosion } \\
\text { - } \quad \text { Abundant meter-long fractures define meter- } \\
\text { scale polygons; fractures are centimeters to decimeters } \\
\text { wide and sand-filled. } \\
\text { - } \quad \text { Dominant grain size in upper } 50 \mathrm{~cm} \text { is below } \\
\text { the resolution of MAHLI, likely silt to clay-sized. } \\
\text { - } \quad \text { Variable concentrations of bright cement-filled } \\
\text { fractures, hairline fractures, and millimeter-scale } \\
\text { bright spherical "hollow nodules", all filled with } \\
\text { calcium sulfate. } \\
\text { - } \quad \text { Dark, raised, intersecting ridges frequently rise } \\
\text { above centimeter-scale polygons in meter-diameter } \\
\text { patches. Ridges dip in various directions, have a } \\
\text { composition similar to that of the host rocks, and } \\
\text { show a small magnesium enrichment. } \\
\text { - } \quad \text { Meter-scale patches contain high concentrations } \\
\text { of millimeter-scale nodules, interpreted as } \\
\text { concretions. Concretions have the same color as } \\
\text { raised ridges. Hollow nodules are also present, as well } \\
\text { as some filled with calcium sulfate. } \\
\text { • } \quad \text { Basaltic composition with 20\% smectite, } \sim 50 \% \\
\text { igneous minerals; and } \sim 30 \% \text { X-ray amorphous } \\
\text { material. Elevated magnetite likely authigenic. }\end{array}$ & $\begin{array}{l}\text { - The upper } 50 \mathrm{~cm} \text { of this unit } \\
\text { weathers recessively and is well } \\
\text { exposed to covered in loose sand. } \\
\text { - } \quad \text { Lower contact: not defined } \\
\text { - Upper contact: sharp with } \\
\text { centimeters of erosional relief, often } \\
\text { overhanging. Regionally mappable due } \\
\text { to topographic expression. }\end{array}$ \\
\hline
\end{tabular}




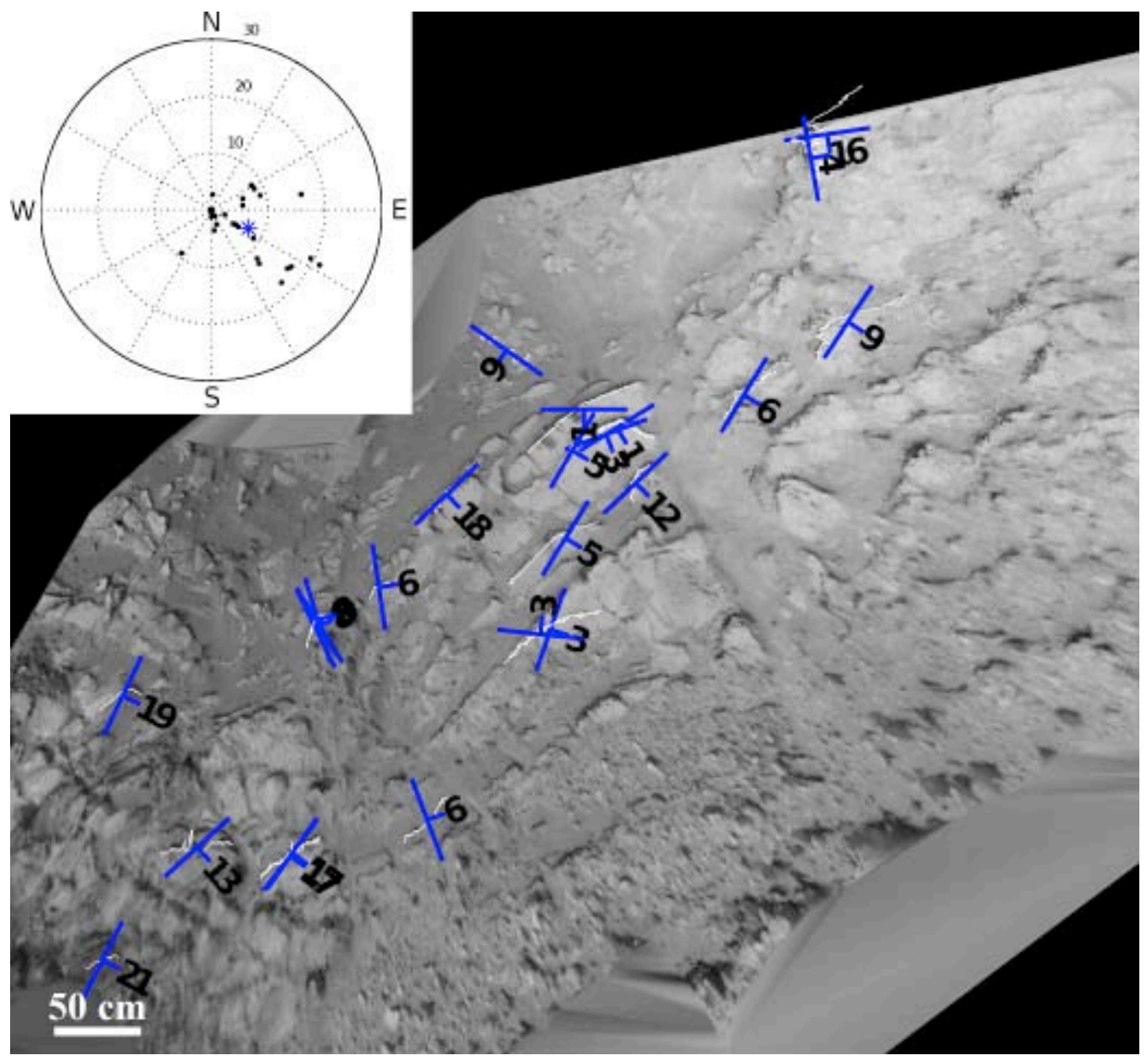

Figure S1. Three-dimensional bedding orientation measurements were extracted from Sol 120 Navcam images of the outcrop, which have been vertically projected in this map. Measurements were made via orthogonal regression, via the method of Lewis et al. (99). 
Dip marks denote individual measurements of bedding traces, shown in white. The polar plot shows each measurement that satisfied our error constraints $(\mathrm{N}=25)$, along with the mean bedding attitude in blue. In general, cross-strata at Shaler dip to the southeast, at a mean dip of 7 degrees, oriented 64 degrees south of east. Although individual measurements show some scatter in dip azimuth, nearly all beds are oriented within 90 degrees of the inferred mean flow direction, consistent with fluvial transport and associated bedform geometries. See Supplementary Text, below, for image IDs.

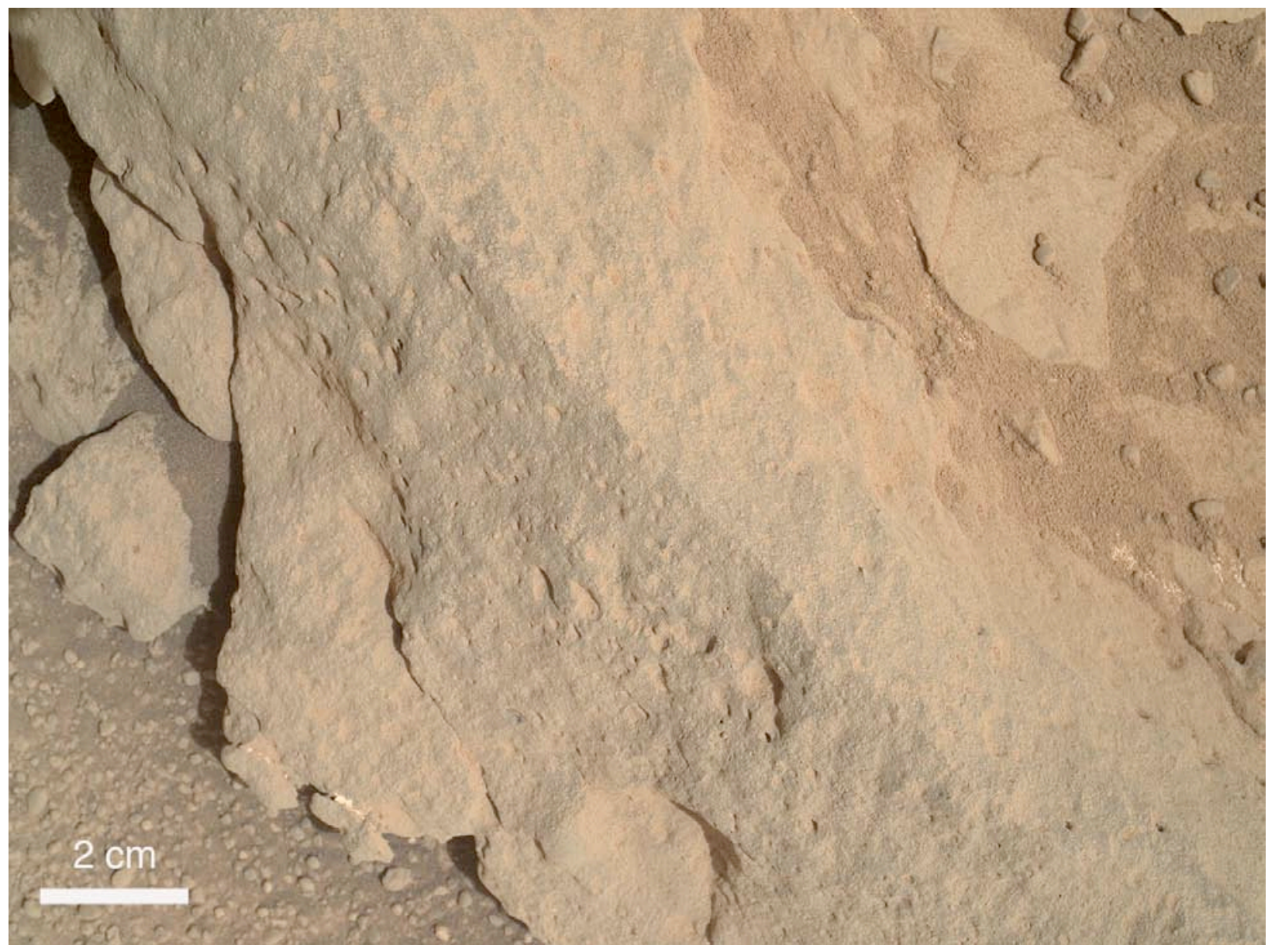

Figure S2. Texture of the "snake" as seen by MAHLI on Sol 149 (6 Jan 2013). Note uniformly fine grain size and presence of pits that may reflect void spaces and, in some cases, erosion of softer components that may represent intraclasts. Image ID: 0149MH0000750010101287C00. 
Supplementary Text: Drill testing of rock hardness

Data collected during terrestrial drill testing on relevant analog samples provide constraints on the physical properties of the rocks drilled at the John Klein and Cumberland drill sites on Mars. The first two analogs consisted of a feldspathic sandstone and a mud/siltstone collected from the Pliocene age Ridge Basin Group, north of the Golden State Highway Old Road, below the Pyramid Lake Dam north of Castaic, CA. These rocks are estimated to be 5-10 million years old, and buried to depths of several kilometers. The third was a pure kaolinite, obtained from the Standard Industrial Mineral mine in Bishop, $\mathrm{CA}$, and the fourth was a large sample of anhydrite-gypsum collected from the Fish Creek Gypsum deposit located in the Salton Trough, south west of the Salton Sea, CA and owned by U. S. Gypsum Mine company.

Drill testing was performed in a drill hardware testbed at the NASA Jet Propulsion Laboratory that houses a flight duplicate MSL drill assembly (100). The drill is mounted to a stage that holds the drill system in place as the rotary percussion drill bit and surrounding sample acquisition tube are fed into rock samples using flight-like drilling algorithms. The drill and its supporting hardware are contained within a vacuum chamber and tests were performed under Mars ambient atmospheric pressure ( 10mbar) during drill testing. In an attempt to more closely replicate the likely hydration state of rocks on Mars, all analogue rock samples were baked in an oven at $110^{\circ} \mathrm{C}$ for a period not less than 2 days prior to drilling in order to drive off adsorbed and loosely bound water to better resemble conditions expected to be present on target rocks on Mars.

While the Curiosity rover does not possess a dedicated instrument for direct determination of rock hardness, a hardness test procedure that uses the drill hardware for in situ determination of rock hardness and cohesiveness has been developed. MSL "Hardness tests" are performed by measuring the depth of penetration of MSL's spade-shaped drill bit tip after a number of discrete motions that result in drill-rock interaction with a nonrotating drill bit. These include depth measurements after the drill bit is loaded against the rock surface with a $130 \mathrm{~N}$ force, after the drill is "tapped" against the rock with a single tap of the percussion actuator, and six subsequent depth of penetration measurements after the drill bit is advanced (without rotation) into the rock at increasing levels of percussion energy. The 6 percuss levels increase in energy with level 1-6 having 0.05 J per blow, 0.20 , $0.31,0.45,0.61$, to $0.81 \mathrm{~J}$ per blow, respectively. The results of these hardness tests provide insight into the relative resistance to penetration of various analogue rock samples for comparison to data collected during drilling operations on Mars. Figure S3 plots our hardness test results for the four analog samples discussed above along with hardness test results from the John Klein and Cumberland drill samples collected by the Curiosity rover on Mars. Note that hardness tests were performed at two locations on the John Klein rock face; one for a mini-drill hole ( $\sim 20 \mathrm{~mm}$ total penetration depth) and one for the full-depth drill hole, from which sample was collected and delivered to Curiosity's onboard analytical instruments. For the Cumberland hardness test, the drill bit tip appears to have advanced deeper into the rock for a given step in the test procedure. In fact, the Cumberland hardness test was terminated at Step 8 because a depth $>0.8 \mathrm{~mm}$ was achieved. Altogether 
these observations suggest that the Cumberland rock target was less resistant to penetration (i.e., softer) than the John Klein target.

A somewhat different picture emerges from Rate of Penetration (ROP) data, which measures the speed at which the drill bit and its surrounding sample acquisition tube are fed into a rock. While this data is a complex function of the intrinsic rock hardness, the cohesive strength of rock, and the engineering parameters of the drill system, it is interesting to compare data from our analogue samples to ROP data collected on Mars. ROP data collection occurs during rotary-percussive drilling, after the hardness test is performed and after a series of rotary-percussion "hole start" motions are performed that effectively create a shallow pilot hole to keep the drill bit from walking across the rock face during the drilling operation. As shown in Figure S4, the John Klein and Cumberland ROP data fall in between the feldspathic sandstone and kaolinite test data, and appear most similar to data collected on the Ridge group mud/siltstone and the anhydrite-gypsum from the Salton Sea. It is important to note that for in situ drilling operations on Mars, the percussion level was intentionally limited to a level lower than the drill system's maximum percussion level, owing to hardware safety concerns for first time drilling operations. These limits were not applied during analogue drill testing on Earth. Therefore, it is possible that a faster ROP could have been realized during John Klein drilling operations had the percussion level been allowed to advance to higher levels. Therefore, the ROP data for John Klein should probably be considered a lower limit on the ROP for this in situ drilling operation. 


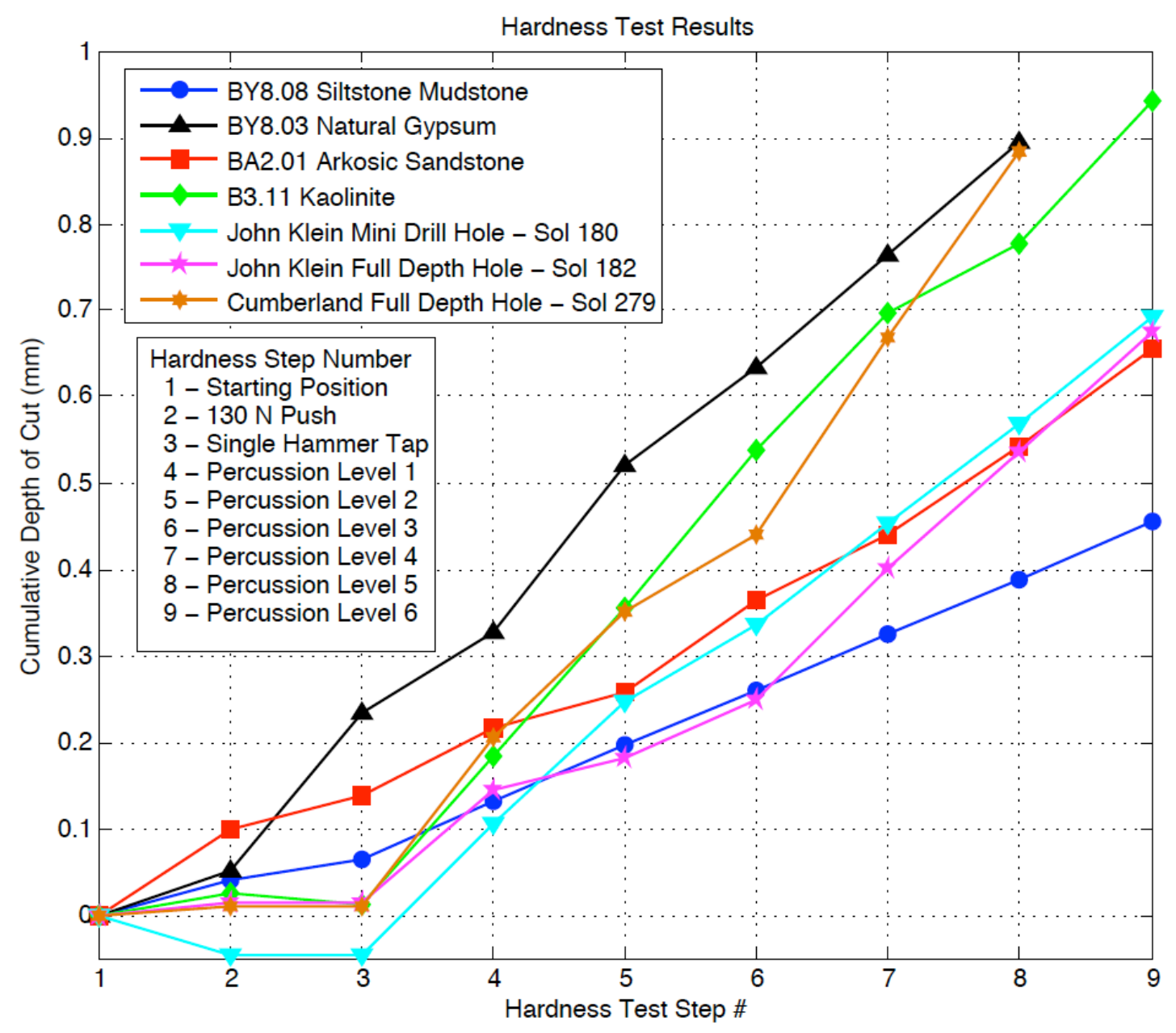

Figure S3. Hardness test results for analogue samples plotted together with the John Klein and Cumberland data on a graph of cumulative depth of cut ( $\mathrm{mm}$ ) versus Hardness test step \#. 


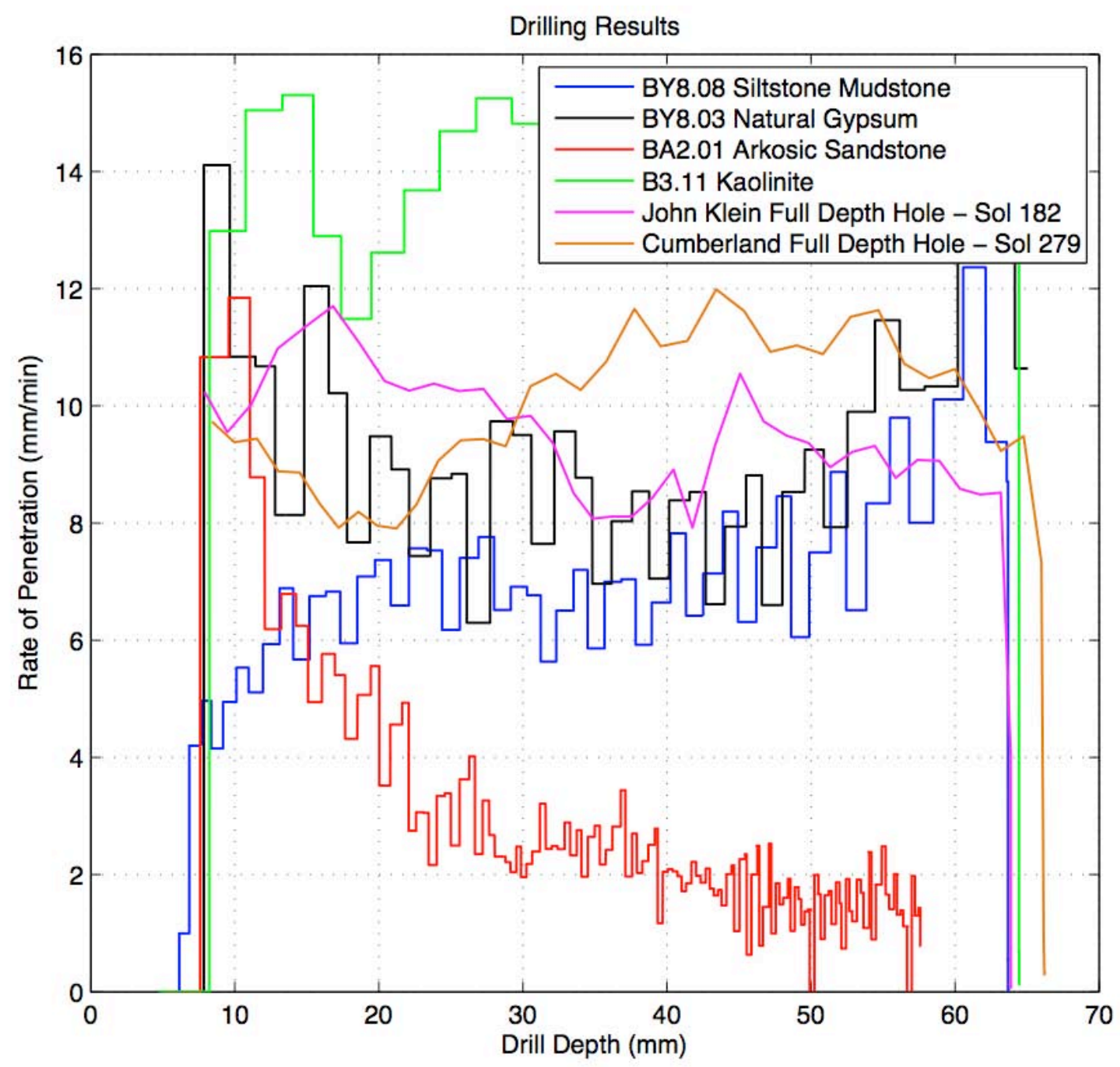

Figure S4. Rate of Penetration (ROP) results for analog samples plotted together with the John Klein and Cumberland data on a graph of ROP ( $\mathrm{mm} / \mathrm{min})$ against drill depth $(\mathrm{mm})$. 
Table S2. Image Identification Numbers for Mosaics

Figure 3 Image IDs :

0137ML0008180080104153E01_DXXX, 0137ML0008180090104154E01_DXXX, 0137ML0008180100104155E01_DXXX, 0137ML0008180110104156E01_DXXX, 0137ML0008180120104157E01_DXXX, 0137ML0008180130104158E01_DXXX, 0137ML0008180140104159E01_DXXX, 0137ML0008180150104160E01_DXXX, 0137ML0008180160104161E01_DXXX, 0137ML0008180170104162E01_DXXX, 0137ML0008180340104179E01_DXXX, 0137ML0008180350104180E01_DXXX, 0137ML0008180360104181E01_DXXX, 0137ML0008180370104182E01_DXXX, 0137ML0008180380104183E01_DXXX, 0137ML0008180390104184E01_DXXX, 0137ML0008180400104185E01_DXXX, 0137ML0008180410104186E01_DXXX, 0137ML0008180420104187E01_DXXX, 0137ML0008180430104188E01_DXXX, 0137ML0008180570104202E01_DXXX, 0137ML0008180580104203E01_DXXX, 0137ML0008180590104204E02_DXXX, 0137ML0008180600104205E01_DXXX, 0137ML0008180610104206E01_DXXX, 0137ML0008180620104207E01_DXXX, 0137ML0008180630104208E01_DXXX, 0137ML0008180640104209E01_DXXX, 0137ML0008180650104210E01_DXXX, 0137ML0008180660104211E01_DXXX, 0137ML0008180800104225E01_DXXX, 0137ML0008180810104226E01_DXXX, 0137ML0008180820104227E01_DXXX, 0137ML0008180830104228E02_DXXX, 0137ML0008180840104229E01_DXXX, 0137ML0008180850104230E01_DXXX, 0137ML0008180860104231E01_DXXX, 0137ML0008180870104232E01_DXXX, 0137ML0008180880104233E01_DXXX

Figure 7 Image IDs:

0164MR0008850030201592E01_DXXX, 0164MR0008850050201594E01_DXXX, 0164MR0008850060201595E01_DXXX, 0164MR0008850070201596E01_DXXX, 0164MR0008850100201599E01_DXXX, 0164MR0008850110201600E01_DXXX, 0164MR0008850120201601E01_DXXX, 0164MR0008850130201602E01_DXXX

Figure S1 Image IDs:

NLA_408156277EDR_F0050742NCAM00213M1.IMG, NLA_408156312EDR_F0050742NCAM00215M1.IMG, NLA_408156347EDR_F0050742NCAM00215M1.IMG, NLA_408156382EDR_F0050742NCAM00215M1.IMG 
Supplementary Text: Mars Science Laboratory (MSL) Science Team

\author{
Aalto University \\ Osku Kemppinen
}

Applied Physics Laboratory (APL) at Johns Hopkins University

Nathan Bridges, Jeffrey R. Johnson, Michelle Minitti

Applied Research Associates, Inc. (ARA)

David Cremers

Arizona State University (ASU)

James F. Bell III, Lauren Edgar, Jack Farmer, Austin Godber, Meenakshi Wadhwa, Danika Wellington

Ashima Research

Ian McEwan, Claire Newman, Mark Richardson

\title{
ATOS Origin
}

Antoine Charpentier, Laurent Peret

Australian National University (ANU)

Penelope King

Bay Area Environmental Research Institute (BAER)

Jennifer Blank

Big Head Endian LLC

Gerald Weigle 


\section{Brock University}

Mariek Schmidt

\section{Brown University}

Shuai Li, Ralph Milliken, Kevin Robertson, Vivian Sun

\section{California Institute of Technology (Caltech)}

Michael Baker, Christopher Edwards, Bethany Ehlmann, Kenneth Farley, Jennifer Griffes, John Grotzinger, Hayden Miller, Megan Newcombe, Cedric Pilorget, Melissa Rice, Kirsten Siebach, Katie Stack, Edward Stolper

\section{Canadian Space Agency (CSA)}

Claude Brunet, Victoria Hipkin, Richard Léveillé, Geneviève Marchand, Pablo Sobrón Sánchez

\section{Capgemini France}

Laurent Favot

\section{Carnegie Institution of Washington}

George Cody, Andrew Steele

\section{Carnegie Mellon University}

Lorenzo Flückiger, David Lees, Ara Nefian

\section{Catholic University of America}

Mildred Martin

\section{Centre National de la Recherche Scientifique (CNRS)}

Marc Gailhanou, Frances Westall, Guy Israël

\section{Centre National d'Etudes Spatiales (CNES)}

Christophe Agard, Julien Baroukh, Christophe Donny, Alain Gaboriaud, Philippe Guillemot, Vivian Lafaille, Eric Lorigny, Alexis Paillet, René Pérez, Muriel Saccoccio, Charles Yana 


\section{Centro de Astrobiología (CAB)}

Carlos Armiens-Aparicio, Javier Caride Rodríguez, Isaías Carrasco Blázquez, Felipe Gómez Gómez , Javier Gómez-Elvira, Sebastian Hettrich, Alain Lepinette Malvitte, Mercedes Marín Jiménez, Jesús Martínez-Frías, Javier Martín-Soler, F. Javier Martín-Torres, Antonio Molina Jurado, Luis Mora-Sotomayor, Guillermo Muñoz Caro, Sara Navarro López, Verónica Peinado-González, Jorge Pla-García, José Antonio Rodriguez Manfredi, Julio José Romeral-Planelló, Sara Alejandra Sans Fuentes, Eduardo Sebastian Martinez, Josefina Torres Redondo, Roser Urqui-O'Callaghan, María-Paz Zorzano Mier

\section{Chesapeake Energy}

Steve Chipera

\section{Commissariat à l'Énergie Atomique et aux Énergies Alternatives (CEA)}

Jean-Luc Lacour, Patrick Mauchien, Jean-Baptiste Sirven

\section{Concordia College}

Heidi Manning

\section{Cornell University}

Alberto Fairén, Alexander Hayes, Jonathan Joseph, Steven Squyres, Robert Sullivan, Peter Thomas

\section{CS Systemes d'Information}

Audrey Dupont

\section{Delaware State University}

Angela Lundberg, Noureddine Melikechi, Alissa Mezzacappa

\section{Denver Museum of Nature \& Science}

Julia DeMarines, David Grinspoon

\section{Deutsches Zentrum für Luft- und Raumfahrt (DLR)}


Günther Reitz

eINFORMe Inc. (at NASA GSFC)

Benito Prats

Finnish Meteorological Institute

Evgeny Atlaskin, Maria Genzer, Ari-Matti Harri, Harri Haukka, Henrik Kahanpää, Janne Kauhanen, Osku Kemppinen, Mark Paton, Jouni Polkko, Walter Schmidt, Tero Siili

\section{GeoRessources}

Cécile Fabre

Georgia Institute of Technology

James Wray, Mary Beth Wilhelm

Géosciences Environnement Toulouse (GET)

Franck Poitrasson

Global Science \& Technology, Inc.

Kiran Patel

Honeybee Robotics

Stephen Gorevan, Stephen Indyk, Gale Paulsen

Imperial College

Sanjeev Gupta

Indiana University Bloomington

David Bish, Juergen Schieber 
Institut d'Astrophysique Spatiale (IAS)

Brigitte Gondet, Yves Langevin

Institut de Chimie des Milieux et Matériaux de Poitiers (IC2MP)

Claude Geffroy

Institut de Recherche en Astrophysique et Planétologie (IRAP), Université de Toulouse

David Baratoux, Gilles Berger, Alain Cros, Claude d'Uston, Olivier Forni, Olivier Gasnault, Jérémie Lasue, QiuMei Lee, Sylvestre Maurice, Pierre-Yves Meslin, Etienne Pallier, Yann Parot, Patrick Pinet, Susanne Schröder, Mike Toplis

Institut des Sciences de la Terre (ISTerre)

Éric Lewin

inXitu

Will Brunner

Jackson State University

Ezat Heydari

Jacobs Technology

Cherie Achilles, Dorothy Oehler, Brad Sutter

Laboratoire Atmosphères, Milieux, Observations Spatiales (LATMOS)

Michel Cabane, David Coscia, Guy Israël, Cyril Szopa

Laboratoire de Géologié de Lyon : Terre, Planète, Environnement (LGL-TPE)

Gilles Dromart

Laboratoire de Minéralogie et Cosmochimie du Muséum (LMCM) 
François Robert, Violaine Sautter

Laboratoire de Planétologie et Géodynamique de Nantes (LPGN)

Stéphane Le Mouélic, Nicolas Mangold, Marion Nachon

Laboratoire Génie des Procédés et Matériaux (LGPM)

Arnaud Buch

Laboratoire Interuniversitaire des Systèmes Atmosphériques (LISA)

Fabien Stalport, Patrice Coll, Pascaline François, François Raulin, Samuel Teinturier

Lightstorm Entertainment Inc.

James Cameron

Los Alamos National Lab (LANL)

Sam Clegg, Agnès Cousin, Dorothea DeLapp, Robert Dingler, Ryan Steele Jackson, Stephen Johnstone, Nina Lanza, Cynthia Little, Tony Nelson, Roger C. Wiens, Richard B. Williams

\section{Lunar and Planetary Institute (LPI)}

Andrea Jones, Laurel Kirkland, Allan Treiman

\section{Malin Space Science Systems (MSSS)}

Burt Baker, Bruce Cantor, Michael Caplinger, Scott Davis, Brian Duston, Kenneth Edgett, Donald Fay, Craig Hardgrove, David Harker, Paul Herrera, Elsa Jensen, Megan R. Kennedy, Gillian Krezoski, Daniel Krysak, Leslie Lipkaman, Michael Malin, Elaina McCartney, Sean McNair, Brian Nixon, Liliya Posiolova, Michael Ravine, Andrew Salamon, Lee Saper, Kevin Stoiber, Kimberley Supulver, Jason Van Beek, Tessa Van Beek, Robert Zimdar

\section{Massachusetts Institute of Technology (MIT)}

Katherine Louise French, Karl Iagnemma, Kristen Miller, Roger Summons

Max Planck Institute for Solar System Research 
Fred Goesmann, Walter Goetz, Stubbe Hviid

\section{Microtel}

Micah Johnson, Matthew Lefavor, Eric Lyness

\section{Mount Holyoke College}

Elly Breves, M. Darby Dyar, Caleb Fassett

\section{NASA Ames}

David F. Blake, Thomas Bristow, David DesMarais, Laurence Edwards, Robert Haberle, Tori Hoehler, Jeff Hollingsworth, Melinda Kahre, Leslie Keely, Christopher McKay, Mary Beth Wilhelm

\section{NASA Goddard Space Flight Center (GSFC)}

Lora Bleacher, William Brinckerhoff, David Choi, Pamela Conrad, Jason P. Dworkin, Jennifer Eigenbrode, Melissa Floyd, Caroline Freissinet, James Garvin, Daniel Glavin, Daniel Harpold, Andrea Jones, Paul Mahaffy, David K. Martin, Amy McAdam, Alexander Pavlov, Eric Raaen, Michael D. Smith, Jennifer Stern, Florence Tan, Melissa Trainer

\section{NASA Headquarters}

Michael Meyer, Arik Posner, Mary Voytek

\section{NASA Jet Propulsion Laboratory (JPL)}

Robert C, Anderson, Andrew Aubrey, Luther W. Beegle, Alberto Behar, Diana Blaney, David Brinza, Fred Calef, Lance Christensen, Joy A. Crisp, Lauren DeFlores, Bethany Ehlmann, Jason Feldman, Sabrina Feldman, Gregory Flesch, Joel Hurowitz, Insoo Jun, Didier Keymeulen, Justin Maki, Michael Mischna, John Michael Morookian, Timothy Parker, Betina Pavri, Marcel Schoppers, Aaron Sengstacken, John J. Simmonds, Nicole Spanovich, Manuel de la Torre Juarez, Ashwin R. Vasavada, Christopher R. Webster, Albert Yen

\section{NASA Johnson Space Center (JSC)}

Paul Douglas Archer, Francis Cucinotta, John H. Jones, Douglas Ming, Richard V. Morris, Paul Niles, Elizabeth Rampe

\section{Nolan Engineering}

Thomas Nolan 
Oregon State University

Martin Fisk

Piezo Energy Technologies

Leon Radziemski

\section{Planetary Science Institute}

Bruce Barraclough, Steve Bender, Daniel Berman, Eldar Noe Dobrea, Robert Tokar, David Vaniman, Rebecca M. E. Williams, Aileen Yingst

\section{Princeton University}

Kevin Lewis

Rensselaer Polytechnic Institute (RPI)

Laurie Leshin

Retired

Timothy Cleghorn, Wesley Huntress, Gérard Manhès

\section{Salish Kootenai College}

Judy Hudgins, Timothy Olson, Noel Stewart

Search for Extraterrestrial Intelligence Institute (SETI I)

Philippe Sarrazin

\section{Smithsonian Institution}

John Grant, Edward Vicenzi, Sharon A. Wilson

\section{Southwest Research Institute (SwRI)}


Mark Bullock, Bent Ehresmann, Victoria Hamilton, Donald Hassler, Joseph Peterson, Scot Rafkin, Cary Zeitlin

\section{Space Research Institute}

Fedor Fedosov, Dmitry Golovin, Natalya Karpushkina, Alexander Kozyrev, Maxim Litvak, Alexey Malakhov, Igor Mitrofanov, Maxim Mokrousov, Sergey Nikiforov, Vasily Prokhorov, Anton Sanin, Vladislav Tretyakov, Alexey Varenikov, Andrey Vostrukhin, Ruslan Kuzmin

\section{Space Science Institute (SSI)}

Benton Clark, Michael Wolff

\section{State University of New York (SUNY) Stony Brook}

Scott McLennan

\section{Swiss Space Office}

Oliver Botta

\section{TechSource}

Darrell Drake

\section{Texas A\&M}

Keri Bean, Mark Lemmon

\section{The Open University}

Susanne P. Schwenzer

\section{United States Geological Survey (USGS) Flagstaff}

Ryan B. Anderson, Kenneth Herkenhoff, Ella Mae Lee, Robert Sucharski

\section{Universidad de Alcalá}

Miguel Ángel de Pablo Hernández, Juan José Blanco Ávalos, Miguel Ramos 
Universities Space Research Association (USRA)

Myung-Hee Kim, Charles Malespin, Ianik Plante

University College London (UCL)

Jan-Peter Muller

University Nacional Autónoma de México (UNAM)

Rafael Navarro-González

University of Alabama

Ryan Ewing

University of Arizona

William Boynton, Robert Downs, Mike Fitzgibbon, Karl Harshman, Shaunna Morrison

University of California Berkeley

William Dietrich, Onno Kortmann, Marisa Palucis

University of California Davis

Dawn Y. Sumner, Amy Williams

University of California San Diego

Günter Lugmair

University of California San Francisco

Michael A. Wilson

University of California Santa Cruz

David Rubin 


\section{University of Colorado Boulder}

Bruce Jakosky

\section{University of Copenhagen}

Tonci Balic-Zunic, Jens Frydenvang, Jaqueline Kløvgaard Jensen, Kjartan Kinch, Asmus Koefoed, Morten Bo Madsen, Susan Louise Svane Stipp

\section{University of Guelph}

Nick Boyd, John L. Campbell, Ralf Gellert, Glynis Perrett, Irina Pradler, Scott VanBommel

\section{University of Hawai'i at Manoa}

Samantha Jacob, Tobias Owen, Scott Rowland

University of Helsinki

Evgeny Atlaskin, Hannu Savijärvi

\section{University of Kiel}

Eckart Boehm, Stephan Böttcher, Sönke Burmeister, Jingnan Guo, Jan Köhler, César Martín García, Reinhold Mueller-Mellin, Robert Wimmer-Schweingruber

\section{University of Leicester}

John C. Bridges

\section{University of Maryland}

Timothy McConnochie

\section{University of Maryland Baltimore County}

Mehdi Benna, Heather Franz

University of Maryland College Park 
Hannah Bower, Anna Brunner

University of Massachusetts

Hannah Blau, Thomas Boucher, Marco Carmosino

\section{University of Michigan Ann Arbor}

Sushil Atreya, Harvey Elliott, Douglas Halleaux, Nilton Rennó, Michael Wong

\section{University of Minnesota}

Robert Pepin

\section{University of New Brunswick}

Beverley Elliott, John Spray, Lucy Thompson

\section{University of New Mexico}

Suzanne Gordon, Horton Newsom, Ann Ollila, Joshua Williams

University of Queensland

Paulo Vasconcelos

University of Saskatchewan

Jennifer Bentz

University of Southern California (USC)

Kenneth Nealson, Radu Popa

\section{University of Tennessee Knoxville}

Linda C. Kah, Jeffrey Moersch, Christopher Tate

\section{University of Texas at Austin}


Mackenzie Day, Gary Kocurek

University of Washington Seattle

Bernard Hallet, Ronald Sletten

University of Western Ontario

Raymond Francis, Emily McCullough

University of Winnipeg

Ed Cloutis

Utrecht University

Inge Loes ten Kate

Vernadsky Institute

Ruslan Kuzmin

Washington University in St. Louis (WUSTL)

Raymond Arvidson, Abigail Fraeman, Daniel Scholes, Susan Slavney, Thomas Stein, Jennifer Ward

Western University

Jeffrey Berger

York University

John E. Moores 